\title{
Sensory and motor secondary symptoms as indicators of brain vulnerability
}

Nava Levit-Binnun ${ }^{1 *}$, Michael Davidovitch ${ }^{1,2}$ and Yulia Golland ${ }^{1}$

\begin{abstract}
In addition to the primary symptoms that distinguish one disorder from the next, clinicians have identified, yet largely overlooked, another set of symptoms that appear across many disorders, termed secondary symptoms. In the emerging era of systems neuroscience, which highlights that many disorders share common deficits in global network features, the nonspecific nature of secondary symptoms should attract attention. Herein we provide a scholarly review of the literature on a subset of secondary symptoms--sensory and motor. We demonstrate that their pattern of appearance--across a wide range of psychopathologies, much before the full-blown disorder appears, and in healthy individuals who display a variety of negative symptoms--resembles the pattern of appearance of network abnormalities. We propose that sensory and motor secondary symptoms can be important indicators of underlying network aberrations and thus of vulnerable brain states putting individuals at risk for psychopathology following extreme circumstances.
\end{abstract}

Keywords: Motor, Network neuroscience, Networks, Resilience, Secondary symptoms, Sensory, Vulnerability

\section{Introduction}

In the clinical literature, disorders are characterized mainly by their distinguishing symptoms and behaviors, often referred to as the primary symptoms. For example, autism spectrum disorder (ASD) is defined by difficulties in communication and restricted behavior, attention-deficit/ hyperactivity disorder (ADHD) by attention deficits and schizophrenia by reality distortion. In addition to these primary symptoms that distinguish one disorder from the next, there is another set of symptoms that appear across many disorders, termed secondary symptoms or nonspecific signs. Secondary symptoms refers to subtle impairments in motor coordination, complex motor sequencing, sensory integration and regulation, sleep and feeding difficulties, as well as difficulties in self-regulation $[1,2]$. Neurologists believe that secondary symptoms reflect nonlocalizable disturbances in connections between subcortical and cortical regions or among cortical regions [2]. Numerous publications have described the existence of these secondary symptoms in association with a variety of disorders. Yet, intriguingly, this body of work has

\footnotetext{
* Correspondence: navalb@idc.ac.il

'Interdisciplinary Center (IDC), Sagol Unit for Applied Neuroscience, School of Psychology, POB 167, Herzliya 46150, Israel

Full list of author information is available at the end of the article
}

been largely overlooked [3,4], perhaps because of the nonspecific nature of these "low-level" symptoms and the difficulty in relating them to the specific high-level impairments of the different disorders.

Although signs that appear across disorders may not be informative for understanding specific disorders, they may be highly relevant to understanding general characteristics of the brain in psychopathological states [4]. Indeed, the recent emergence of systems neuroscience, a promising field that calls for a paradigm shift in the way we view healthy and psychopathological brain states, suggests that invariant characteristics observed across psychopathologies may provide important information. Unlike traditional approaches that have focused on uniquely distinguishing one disorder from the next, there is an attempt in systems neuroscience to unify a wide range of psychopathologies and describe their common characteristics. That is, this field highlights that many disorders share common deficits in global network features [5]. The main focus of systems neuroscience lies in characterizing the abnormal brain architecture that underlies many disorders and describing the resulting consequences for the dynamic function of the brain network and its ability to maintain functional homeostasis.

\section{Biomed Central}

(C) 2013 Levit-Binnun et al.; licensee BioMed Central Ltd. This is an Open Access article distributed under the terms of the Creative Commons Attribution License (http://creativecommons.org/licenses/by/2.0), which permits unrestricted use, distribution, and reproduction in any medium, provided the original work is properly cited. 
Indeed, one of the major consequences of the abnormalities in brain architecture, observed in many disorders, is the loss of robustness of the brain network to perturbations. This suggests that brains with abnormalities in brain architecture are more vulnerable and that unfavorable circumstances (for example, psychological life stressors, chemical stressors, brain hemorrhages or aberrations in anatomical brain structures during development or neurodegeneration) can cause them to deviate from homeostasis.

Herein we propose an integrative framework in which secondary symptoms represent the behavioral manifestations of the brain's abnormal architecture and are thus indicators of network vulnerability. To that end, we provide a systematic review of sensory and motor secondary symptoms and show that although secondary symptoms and network aberrations come from different levels of description-one at the behavioral level and the other at the network level-they display similar patterns of occurrence. That is, sensory and motor symptoms and network aberrations not only occur across a wide range of psychopathologies but also are detectable much before the full-blown disorder appears, in both at-risk populations and in healthy individuals who display a variety of negative symptoms. We then provide theoretical and empirical support that the behavioral level and the network level may be related and propose that secondary symptoms can be important indicators of vulnerable brain states at risk to psychopathology. In other words, the appearance of secondary symptoms in an individual may indicate that his brain is in a less resilient state, and thus he has a higher probability of developing psychopathology following unfavorable circumstances. The novel integrative approach used here yields practical clinical benefits and advances our understanding of the developmental paths of psychopathologies.

\section{Review}

In this section, we review reports of sensory and motor secondary symptoms from a wide range of disciplines. We define sensory and motor symptoms broadly and focus on indications of abnormalities and difficulties observed in these processes. The primary purpose of this section is to reveal an underlying pattern of occurrence of these abnormalities in relation to psychopathology. Therefore, we investigated the occurrence of sensory and motor abnormalities during active states of psychopathology. In addition, we examined their occurrence before the psychopathology is evident, when there is a propensity to develop a psychopathology, and even in healthy, undiagnosed individuals at no apparent risk for psychopathology but with more negative symptoms than those found in the average healthy population.

\section{Methods}

We conducted a systematic review of the literature on studies that linked signs of sensory and motor abnormalities to a wide range of developmental, psychiatric and/or affective and neurodegenerative psychopathologies. We used search terms that are variations of words related to sensory and motor abnormalities (see Table 1). Since neurologists often term the co-occurrence of sensory and motor abnormalities neurological soft signs (NSSs) [2], we also included this term in our search. The search was conducted in the following databases: APA PsychNET (http://psycnet.apa.org/), MEDLINE, Academic Search Complete (http://www.ebscohost.com/academic/academic-search-complete), Psychology and Behavioral Sciences Collection (http://www.ebscohost.com/academic/psychology-behavioral-sciences-collection), SocINDEX (http:// www.ebscohost.com/academic/socindex-with-full-text) and Education Resource Information Center (ERIC; http:// eric.ed.gov/). The psychopathologies included in this search were autism, ADHD, dyslexia, learning disabilities, language disorders, schizophrenia, anxiety, depression, posttraumatic stress disorder (PTSD), obsessive-compulsive disorder (OCD), bipolar affective disorder, borderline personality disorder, Alzheimer disease (AD) and traumatic brain injury. We also searched for words related to healthy aging. In order to account for differences in definitions across disciplines (for example, schizophrenia can be characterized as a psychiatric disorder or a developmental one [6]), we included general search terms such as "psychiatric," "developmental" or "affective." The specific search terms used in this review, as well as exclusion criteria, are displayed in Table 1.

\section{Criteria for exclusion}

Only reports that compared the appearance of sensory and/or motor abnormalities observed in individuals with a psychopathology with that of healthy human controls were accepted into the review. Comorbidities (for example, ADHD together with developmental coordination disorder) were excluded. As mentioned, our goal was to present a pattern of appearance of secondary symptoms as reported by researchers and clinicians. Thus, we did not include reviews and meta-analyses. We also did not distinguish between research methodologies (questionnaires, retrospective studies, prospective studies and objective tests), as long as they presented quantifiable data that could determine whether or not a difference was observed between the psychopathology tested and healthy controls. Thus, single-case studies, qualitative studies and intervention studies were not included. In addition, most of the vast neurophysiological literature fell outside the scope of this review (for example, anatomical, sensory event-related potentials, imaging and electrophysiological 


\section{Category} Search terms

Motor (motor OR movement OR motion OR "fine motor" OR "gross motor") AND (abnormalities OR impairment OR difficulties OR dysfunction OR dysfunctions OR function OR disturbance $O R$ disturbances $O R$ deficient $O R$ deficiency $O R$ performance OR ability OR coordination OR skills OR profile OR behavior OR behaviour OR development OR synchrony)

Sensory $\quad$ (sensory OR tactile OR auditory OR somatosensory OR sensorimotor OR balance OR vestibular OR sensation OR "sensory-motor") AND (defensiveness OR modulation $O R$ regulation $O R$ processing $O R$ sensitivity $O R$ abnormalities $O R$ responsivity $O R$ hyperreactivity OR hyporeactivity OR "hyper-reactivity" OR "hypo-reactivity" OR hyperreactivity OR hyporeactivity OR "hyper-reactivity" OR "hypo-reactivity"
impairment OR filtering OR difficulties OR dysfunction OR dysfunctions OR hypersensitivity OR hyposensitivity OR disturbance OR disturbances OR performance OR filtering OR intolerance)

Neurological soft "neurological abnormalities" OR "neurological soft signs" OR "subtle signs neurologic compromise" OR "neurological examination abnormalities" OR "neurological signs" OR "soft signs" OR "neurological examination abnormalities" OR "neuropsychological"

Sleep

(sleep OR sleepiness OR insomnia OR sleep-related) AND (deprivation OR excessive OR symptoms OR regulation OR continuity OR continuity changes OR complaints OR disturbance $O R$ disturbances $O R$ deficits $O R$ deficit OR disruption OR disruptions OR problems OR evaluation OR patterns)

Autism spectrum autism OR ASD OR "autism spectrum" OR "autism spectrum disorder" OR "autistic disorder spectrum" OR "autistic spectrum disorder" OR Asperger OR Asperger's OR alexithymia

Attention-deficit/ ADHD OR "attention deficit hyperactivity disorder" OR "attention-deficit/hyperactivity hyperactivity disorder" OR "attention deficit disorder" OR "attention deficit disorder with hyperactivity" disorder OR "deficit disorder attention" OR "attention difficulties" OR "hyperkinetic syndrome" OR "hyperkinetic disorder" OR "hyperactive child syndrome"

Dyslexia and dyslexia OR "learning disabilities" OR "learning deficits"

learning

disabilities

Language

impairment

Anxiety

Posttraumatic

stress disorder

Depression

"specific language impairment" OR "speech delay" OR SLI

anxiety OR anxious OR emotional behavior OR phobia OR phobias OR avoidant PTSD OR "posttraumatic stress disorder" OR "post-traumatic stress disorder" OR "post traumatic stress disorder"

Bipolar affective "bipolar affective disorder" OR "bipolar disorder" disorder

\section{Exclusion criteria}

In general, we searched for evidence indicating general abnormalities in motor performance. In cases in which little research had been performed on motor aspects of a certain disorder, however, we included studies that focused on more narrow motor tasks, such as finger-tapping. In general, however, we excluded studies that focused exclusively on interaction of motor task and cognitive load handwriting abilities, visuomotor integration, motor imagery, physical fitness, representation of action, mirror neurons, visuospatial guidance of movement during imitation, motor imagery, motor speech impairments, movement planning, repetitive motor behavior, motor restlessness, dyskinesia and gait and/or posture problems.

We excluded animal studies, genetic studies and all studies that investigated sensory abnormalities in the brain via physiological measures (for example, sensory evoked potentials, fMRI studies and startle responses). In addition, we excluded studies dealing with reactivity to pain, sensory impairments (such as impairment in seeing or hearing), eye movements, motion or visuospatial perception, visual acuity, audiovisual speech, sensory memory, timing of sensory processes, sensory gating and speech. In addition, studies that looked at the temperamental aspect of "sensory seeking" were excluded.

Studies that focused on neurological deficits observable as cognitive and/or memory abnormalities were excluded. Only those that related to sensory and motor abnormalities were included.

Studies that focused exclusively on a certain sleep parameter (for example, REM activity, NREM activity, sleep spindle activity, slow-wave activity and K-complex activity) were excluded. In addition, we excluded studies focused on sleep difficulties resulting from sleep apnea or other breathing difficulties.

Studies that focused on higher-order visual and auditory processing abilities (such as speech discrimination) were excluded.

We excluded studies of depression associated with another difficulty, such as migraine, menopause, cancer and chemotherapy. Postpartum depression, perinatal depression and parental depression were also excluded. 
Table 1 Search terms and exclusion criteria ${ }^{a}$ (Continued)

Borderline borderline OR "borderline personality disorder"

personality

disorder

Obsessive- "obsessive compulsive disorder" OR OCD OR "repetitive behavior" OR "repetitive behaviors"

compulsive

disorder

Schizophrenia schizophrenia OR schizophrenic OR schizotypal OR psychosis

and psychosis

Alzheimer "Alzheimer disorder" OR Alzheimer OR Alzheimer's OR dementia

disease

Traumatic brain "traumatic brain injury: OR "traumatic brain injuries" OR TBI

injury

Normal aging

General search "psychiatric disorders" OR "psychiatric disorder" OR "psychotic disorders" OR "psychotic

aging OR older people OR "older adults" OR "elder people" OR "elder adults" OR elderly

terms

"psychiatsic

With regard to the "high-risk" search, we included only studies

"degenerative disorders" OR "neurological disorders

"affective disorders" OR "social-emotional behavior" OR "mood disorder" OR "mood

disorders" OR mood OR "emotional disorders" OR "psychological distress" "high-risk" OR at-

risk OR "at risk" OR "high risk"

${ }^{\mathrm{a} A D H D}$, attention-deficit/hyperactivity disorder; ASD, autism spectrum disorder; fMRI, functional magnetic resonance imaging; NREM, non-rapid eye movement; OCD, obsessive-compulsive disorder; PTSD,

posttraumatic stress disorder; REM, rapid eye movement; $T B 1$, traumatic brain injury. 
studies). Additional exclusion criteria are presented in Table 1.

\section{Division of included studies into four categories}

The studies that were included in the review were divided into four categories: (1) irregularities across disorders: that is, studies demonstrating that sensory and/or motor abnormalities appear in a full-blown psychopathology (for example, sensory abnormalities in individuals with autism); (2) irregularities before primary symptoms: studies demonstrating that sensory and/or motor abnormalities are evident before the full-blown symptoms of a psychopathology appear (for example, a retrospective study showing that children with ADHD displayed motor abnormalities as infants or a prospective study of individuals at risk for schizophrenia who later developed the disorder) or studies of populations considered at risk for a disorder (for example, findings of sensory abnormalities in siblings of patients with autism); (3) irregularities in healthy individuals: studies which assessed rates of sensory and/or motor abnormalities in healthy populations not considered at risk for psychopathology (for example, healthy college students); (4) no difference: studies that indicated no sign of sensory and/or motor abnormalities in relation to psychopathology (for example, no difference between individuals with autism and healthy controls in sensory abnormalities). The fourth category was included to enable a balanced picture.

\section{Results}

Our search revealed more than 330 reports that mentioned sensory or motor irregularities or their combination (that is, NSSs) in relation to psychopathology or symptoms of psychopathology. Dividing them into our four categories revealed a clear pattern of appearance.

\section{Irregularities across disorders}

Two hundred thirty-two reports mentioning sensory or motor irregularities in individuals with psychopathology were found (see Table 2 for details). Although there was variability in the number of published reports relating sensory and/or motor irregularities to specific disorders (ranging from three papers implicating secondary symptoms in PTSD and fifty-two implicating them in autism), we found mentions of sensory and/or motor irregularities for each of the search terms. Only 22 reports found no clear differences between the rate of sensory and/or motor signs in individuals with a psychopathological condition and healthy people (see right column in Table 2).

\section{Irregularities before primary symptoms}

Our search revealed 60 retrospective, prospective and sibling and/or family studies indicating that abnormalities in sensory and motor processes are evident before psychopathology appears and before the full-blown symptoms are visible (see Table 3 for details). Such findings suggest that these irregularities not only are correlated with the disorders but may have a predictive nature as well $[3,229,230]$.

For example, various sensory and motor difficulties precede communication delay and autism symptoms in most infants who later develop ASD $[9,58,232]$ or who are at risk for developing autism [231]. In toddlers at risk for familial dyslexia, researchers found a relationship between motor development at infanthood and the level of language skills at toddlerhood [238]. In a prospective study following 401 toddlers, motor performance was found to be predictive of ADHD [237]. In another study comprising 275 children with ADHD, their siblings and controls, the unaffected siblings displayed intermediate levels of motor problems between the ADHD-affected children and the control subjects [100].

Quite a few studies have reported the existence of sensory and motor signs much sooner than schizophrenia symptoms were evident. For example, a few prospective studies [240-242] found that children who developed schizophrenia as adults took longer to achieve motor milestones and scored significantly worse than controls on motor coordination tasks. Significantly more NSSs were found in children and relatives with a higher genetic risk for schizophrenia $[248,276]$ and in those who later became adult schizophrenics [242]. Moreover, relatives of patients with schizophrenia exhibited levels of NSSs that were intermediate between patients with the full-blown disorder and healthy controls [163-166].

Early motor signs were also predictive of later moodrelated psychopathologies. For example, in a large cohort study of 6,850 children, boys with poor motor skills at age 7 years had more than three times the odds of having maternally rated anxiety at the ages of 11 and 16 years [270]. Another study found that both OCD patients and their unaffected first-degree relatives displayed more motor coordination signs than healthy controls [184]. In several prospective epidemiological studies, an association was found between NSSs and the development of anxiety, depression and obsessive-compulsive symptoms over time $[267,268]$. Interestingly, recent studies on twins have found that NSSs represent vulnerability to PTSD. Not only did combat veterans with PTSD have significantly more NSSs than combat veterans without PTSD, but their unexposed co-twins had significantly more NSSs than the unexposed co-twins of the veterans without PTSD [129,277].

\section{Irregularities in healthy individuals}

Although researchers rarely examine signs of psychopathology in healthy individuals, our search succeeded in revealing 17 studies that reported the occurrence of 
Table 2 Sensory and/or motor irregularities appear across disorders ${ }^{\mathrm{a}}$

\begin{tabular}{|c|c|c|}
\hline Disorder & $\begin{array}{l}\text { Sensory and/or motor irregularities appear more } \\
\text { frequently in disorder than in healthy controls }\end{array}$ & Not different from healthy controls \\
\hline \multirow[t]{6}{*}{ Autism } & Sensory & Sensory \\
\hline & $\begin{array}{l}\text { Adamson et al., 2006; Adrien et al., 1987; Baranek, 1999; Baranek et al., 2007; } \\
\text { Baranek et al., 2006; Baranek et al., 2013; Ben-Sasson et al., 2007; Blakemore } \\
\text { et al., 2006; Blanche et al., 2012; Cascio et al., 2008; Cheung and Siu, 2009; } \\
\text { Crane et al., 2009; Dickie et al., 2009; Dunn et al., 2002; Hilton et al., 2010; } \\
\text { Hochhauser and Engel-Yeger, 2010; Kern et al., 2008; Kern et al., 2007a; Kern } \\
\text { et al., 2007b; Kern et al., 2006; Kern et al., 2007c; Khalfa et al., 2004; Kientz } \\
\text { and Dunn, 1997; Kwakye et al., 2011; Leekam et al., 2007; O'Brien et al., 2009; } \\
\text { Reynolds et al., 2011; Reynolds et al., 2012; Rogers et al., 2003; Siaperas et al., } \\
\text { 2012b; Tavassoli and Baron-Cohen, 2012b; Tomchek and Dunn, 2007; Watling } \\
\text { et al., 2001; Weimer et al., 2001; Woodard et al., } 2012 \text { [7-41] }\end{array}$ & $\begin{array}{l}\text { Fuentes et al., 2011; Güçlü et al., 2007; Jones et al., } \\
\text { 2009; Tavassoli and Baron-Cohen, 2012 [42-45] }\end{array}$ \\
\hline & Motor & Motor \\
\hline & $\begin{array}{l}\text { Dewrang and Sandberg, 2010; Esposito and Venuti, 2008; Freitag et al., 2007; } \\
\text { Gernsbacher et al., 2008; Hilton et al., 2007; Hilton et al., 2012; Lopata et al., } \\
\text { 2007; Pan et al., 2009; Papadopoulos et al., 2012; Sahlander et al., 2008; } \\
\text { Siaperas et al., 2012; Travers et al., 2013; Whyatt and Craig, } 2012 \text { [34,46-57] }\end{array}$ & Ozonoff et al., 2008 [58] \\
\hline & NSS & \\
\hline & $\begin{array}{l}\text { De Jong et al., 2011; Jansiewicz et al., 2006; Jones and Prior, 1985; } \\
\text { Tani et al., } 2006 \text { [59-62] }\end{array}$ & \\
\hline \multirow{4}{*}{$\begin{array}{l}\text { Language } \\
\text { disorders }\end{array}$} & Sensory & \\
\hline & Taal et al., 2013 [63] & \\
\hline & Motor & \\
\hline & $\begin{array}{l}\text { Chuang et al., 2011; Finlay and McPhillips, 2013; Müürsepp et al., 2009; } \\
\text { Owen and McKinlay, 1997; Zelaznik and Goffman, } 2010 \text { [64-68] }\end{array}$ & \\
\hline \multirow[t]{7}{*}{ Dyslexia } & Sensory & Sensory \\
\hline & (Auditory visual processing deficits) & \\
\hline & $\begin{array}{l}\text { Fraser et al., 2010; Georgiou et al., 2012; Heiervang et al., 2002; } \\
\text { White et al., 2006; Wright and Conlon, } 2009 \text { [69-73] }\end{array}$ & Polatajko, 1985; White et al., 2006 [74,75] \\
\hline & (Balance and tactile) & \\
\hline & $\begin{array}{l}\text { Brookes et al., 2010; Cinelli and DePaepe, 1984; Getchell et al., 2007; } \\
\text { Kinnealey, 1989; Needle et al., 2006; Nicolson and Fawcett, } 1994 \text { [76-81] }\end{array}$ & \\
\hline & (Balance and tactile) & \\
\hline & $\begin{array}{l}\text { Bruininks and Bruininks, 1977; Cermak et al., 1990; Durand, 2005; Getchell et al., } \\
\text { 2007; Haslum and Miles, 2007; Maloy and Sattler, 1979; McPhillips and Sheehy, } \\
\text { 2004; Pieters et al., 2012; Trauner et al., 2000; Vuijk et al., 2011; } \\
\text { Westendorp et al., } 2011 \text { [80,82-91] }\end{array}$ & \\
\hline \multirow[t]{6}{*}{ ADHD } & Sensory & Sensory \\
\hline & $\begin{array}{l}\text { Bröring et al., 2008; Cheung and Siu, 2009; Dunn and Bennett, 2002; } \\
\text { Engel-Yeger and Ziv-On, 2011; Lufi and Tzischinsky, 2012; Miller et al., } \\
\text { 2012; Romanos et al., } 2008 \text { [40,92-97] }\end{array}$ & $\begin{array}{l}\text { Gomez and Condon, 1999; Schlee et al., } 2012 \\
{[98,99]}\end{array}$ \\
\hline & Motor & Motor \\
\hline & $\begin{array}{l}\text { Flapper et al., 2006; Chan et al., 2010; Fliers et al., 2009; Fliers et al., 2010; } \\
\text { Goulardins et al., 2013; Harvey et al., 2007; Karatekin et al., 2003; Klimkeit et al., } \\
\text { 2004; Klotz et al., 2012; Meyer and Sagvolden, 2006; Okuda et al., 2011; } \\
\text { Pan et al., 2009; Piek et al., 1999; Rommelse et al., 2007; Slaats-Willemse et al., } \\
2005 \text { [47,100-113] }\end{array}$ & $\begin{array}{l}\text { Kooistra et al., 2005; Lee et al., 2013; Polderman } \\
\text { et al., } 2011 \text { [114-116] }\end{array}$ \\
\hline & NSS & \\
\hline & Chan et al., 2010; Dickstein et al., 2005; Ferrin and Vance, 2012 [102,117,118] & \\
\hline \multirow[t]{2}{*}{ Anxiety } & Motor & Motor \\
\hline & $\begin{array}{l}\text { Ekornås et al., 2010; Kristensen and Torgersen, 2007; } \\
\text { Skirbekk et al., } 2012 \text { [119-121] }\end{array}$ & Jacob et al., 2009 [122] \\
\hline
\end{tabular}


Table 2 Sensory and/or motor irregularities appear across disorders ${ }^{\mathrm{a}}$ (Continued)

\begin{tabular}{|c|c|c|}
\hline & Sensory & \\
\hline & $\begin{array}{l}\text { Erez et al., 2004; Farrow and Coulthard, 2012; Hofmann and } \\
\text { Bitran, } 2007 \text { [123-125] }\end{array}$ & \\
\hline & NSS & \\
\hline & Hollander et al., 1996 [126] & \\
\hline \multirow{2}{*}{$\begin{array}{l}\text { Posttraumatic } \\
\text { stress disorder }\end{array}$} & NSS & NSS \\
\hline & $\begin{array}{l}\text { Gurvits et al., 2000; Gurvits et al., 1993; Gurvits et al., } \\
2006 \text { [127-129] }\end{array}$ & Gurvits et al., 2002 [130] \\
\hline \multirow[t]{4}{*}{ Depression } & Motor & NSS \\
\hline & $\begin{array}{l}\text { Günther et al., 1988; Lohr et al., 2013; Schwartz et al., } \\
1990 \text { [131-133] }\end{array}$ & Zhao et al., 2013 [134] \\
\hline & NSS & \\
\hline & Boks et al., 2004; Manschreck and Ames, 1984 [135,136] & \\
\hline \multirow{4}{*}{$\begin{array}{l}\text { Bipolar affective } \\
\text { disorders }\end{array}$} & Motor & Sensory \\
\hline & Dickstein et al., 2005; Lohr and Caligiuri, 2006 [117,137] & Swiecicki et al., 2009 [138] \\
\hline & NSS & \\
\hline & Negash et al., 2004; Zhao et al., 2013 [134,139] & \\
\hline \multirow{6}{*}{$\begin{array}{l}\text { Borderline } \\
\text { personality } \\
\text { disorder }\end{array}$} & Sensory & Sensory \\
\hline & Brown et al., 2009; Rosenthal et al., 2011 [140,141] & Pavony and Lenzenweger, 2013 [142] \\
\hline & Motor & \\
\hline & Swirsky-Sacchetti et al., 1993 [143] & \\
\hline & NSS & \\
\hline & $\begin{array}{l}\text { De la Fuente et al., 2011; De la Fuente et al., 2006; } \\
\text { Gardner et al., 1987 [144-146] }\end{array}$ & \\
\hline \multirow[t]{6}{*}{ Schizophrenia } & Sensory & Sensory \\
\hline & $\begin{array}{l}\text { Brown et al., 2002; Cheng et al., 2012; Colbert et al., 1959; Emmerich and } \\
\text { Levine, 1970; Ghadirian and Butter, 1978; Kent et al., 2012; Kiss et al., 2010; } \\
\text { Levine and Whitney, 1970; Myers et al., 1973; Ramage et al., } 2012 \text { [147-156] }\end{array}$ & Levy et al., 1978 [157] \\
\hline & Motor & Motor \\
\hline & $\begin{array}{l}\text { Günther et al., 1986; Midorikawa et al., 2008; Sullivan et al., 1994; } \\
\text { Tabarés-Seisdedos et al., } 2003 \text { [158-161] }\end{array}$ & Martin et al., 1995 [162] \\
\hline & NSS & \\
\hline & $\begin{array}{l}\text { Aksoy-Poyraz et al., 2011; Aydemir et al., 2005; Boks et al., 2004; Chan and } \\
\text { Chen, 2007; Chen et al., 2000; Compton et al., 2007; Flyckt et al., 1999; Ismail } \\
\text { et al., 1998; Jaafari et al.,2011; Le Seac'h et al., 2012; Manschreck and Ames, } \\
\text { 1984; Mechri et al., 2009; Mohr et al., 1996; Nucifora and Calandra, 1999; } \\
\text { Sevincok et al., 2004; Shibre et al., 2002; Venkatasubramanian et al., 2003; } \\
\text { Walker and Green, 1982; Yazici et al., 2002; Zhao et al., } 2013 \text { [134-136,163-179] }\end{array}$ & \\
\hline \multirow{5}{*}{$\begin{array}{l}\text { Obsessive- } \\
\text { compulsive } \\
\text { disorder }\end{array}$} & Motor & NSS: \\
\hline & Bloch et al., 2011 [180] & Jaafari et al., 2011 [172] \\
\hline & Sensory & \\
\hline & $\begin{array}{l}\text { Dar et al., 2012; Rieke and Anderson, 2009; Segalàs et al., } \\
2011 \text { [181-183] }\end{array}$ & \\
\hline & NSS & \\
\hline
\end{tabular}


Table 2 Sensory and/or motor irregularities appear across disorders ${ }^{\mathrm{a}}$ (Continued)

\begin{tabular}{|c|c|c|}
\hline & $\begin{array}{l}\text { Bolton et al., 1998; Hollander et al., 1990; Karadag et al., 2011; } \\
\text { Mataix-Cols et al., 2003; Peng et al., 2012 [184-188] }\end{array}$ & \\
\hline \multirow{6}{*}{$\begin{array}{l}\text { Alzheimer } \\
\text { disease }\end{array}$} & Sensory & \\
\hline & $\begin{array}{l}\text { Gallacher et al., 2012; Kato-Narita et al., 2011; Leandri et al., 2009; } \\
\text { Pettersson et al., 2002; Pettersson et al., 2005; Rolland et al., 2009; } \\
\text { Suttanon et al., 2012; Waite et al., } 2000 \text { [189-196] }\end{array}$ & \\
\hline & Motor & \\
\hline & $\begin{array}{l}\text { Kluger et al., 1997; Kluger et al., 1997; Oakley et al., 2003; } \\
\text { Ott et al., 1995; Pettersson et al., } 2005 \text { [193,197-200] }\end{array}$ & \\
\hline & NSS & \\
\hline & Lam et al., 2005; Seidl et al., 2009 [201,202] & \\
\hline \multirow{4}{*}{$\begin{array}{l}\text { Traumatic brain } \\
\text { injury }\end{array}$} & Sensory & \\
\hline & $\begin{array}{l}\text { Gagnon et al., 1998; Galvin et al., 2009; Katz-Leurer et al., 2008; } \\
\text { Kuhtz-Buschbeck et al., } 2003 \text { [203-206] }\end{array}$ & \\
\hline & Motor & \\
\hline & Gagnon et al., 1998 [203] & \\
\hline \multirow[t]{6}{*}{ Normal aging } & Sensory & Sensory \\
\hline & $\begin{array}{l}\text { Cole, 1991; Desrosiers et al., 1996; Fukunaga et al., 2005; Li et al., 2004; } \\
\text { Petrosino and Fucci, 1989; Pohl et al., 2003; Ranganathan et al., 2001; } \\
\text { Schumm et al., 2009; Shimokata and Kuzuyam, 1995; Stevens, 1992; } \\
\text { Stevens and Cruz, 1996; Zhang et al., } 2011 \text { [207-218] }\end{array}$ & Bartoshuk et al., 1986; Elsner, 2001 [219,220] \\
\hline & Motor & Motor \\
\hline & $\begin{array}{l}\text { Ashendorf et al., 2009; Bennett et al., 2012; Kauranen and Vanharanta, } \\
\text { 1996; Smith et al., 1999; Vernazza-Martin et al., } 2008 \text { [221-225] }\end{array}$ & Kleinman, 1982; Santos et al., 2007 [226,227] \\
\hline & NSS & \\
\hline & Chan et al., 2011 [228] & \\
\hline
\end{tabular}

${ }^{\mathrm{a} A D H D}$, attention-deficit/hyperactivity disorder; NSS, neurological soft sign.

sensory and motor abnormalities in healthy individuals. Interestingly, in all of these reports, negative mental symptoms related to psychopathology (for example, higher anxiety and depression levels) were found to correlate with higher rates of sensory and/or motor abnormalities (see Table 4). That healthy individuals with more sensory and motor abnormalities than average also tend to have more negative mental health symptoms suggests that these abnormalities are not the consequence of psychopathology, but rather a characteristic of an underlying vulnerability to it.

For example, healthy individuals with extreme sensory reactivity are more likely to display signs of anxiety and depression [278-281,287,296]. Individuals with extreme sensory reactivity patterns also display higher signs of alexithymia and autistic characteristics [287,289], social phobia [290] and avoidant and borderline personality traits [291,292]. Preschoolers and school-aged children with sensory regulation dysfunction (for example, sensory overresponsivity) were more likely to display early and co-occurring internalizing and externalizing behaviors, lower levels of concurrent adaptive social behaviors and more psychiatric symptoms [293,294]. Similarly, preschoolers with motor coordination difficulties exhibited negative emotional symptoms, such as signs of depression and anxiety [282,288]. This was also shown in a twin study, which found significantly higher levels of anxious and depressive symptomatology in twins with motor abnormalities compared with control twins with no motor difficulties. Moreover, in twins discordant for motor abnormalities, the twin with motor difficulties exhibited more anxious and depressive signs than the co-twin without such difficulties [283].

\section{Summary}

Our systematic review revealed a clear pattern of the appearance of sensory and motor irregularities across developmental, affective and/or psychiatric and degenerative brain psychopathologies. These irregularities not only appear together with the full-blown disorder but also are apparent much before its primary signs, even in individuals who are considered healthy. Although clinicians have long noted the nonspecific nature of sensory and motor signs in relation to many disorders, to the best of our knowledge, this review is the first scholarly demonstration of their pattern of appearance. Notably, other 
Table 3 Sensory and/or motor irregularities appear long before the full-blown symptoms ${ }^{a}$

\begin{tabular}{|c|c|c|c|}
\hline Disorders & & At-risk populations & Prospective and retrospective studies \\
\hline \multirow[t]{3}{*}{$\begin{array}{l}\text { Developmental } \\
\text { disorders }\end{array}$} & Autism & $\begin{array}{l}\text { Bryson et al., 2007; Mulligan and White, 2012, Bhat et al., } \\
\text { 2012; Bryson et al., 2007; Landa and Garrett-Mayer, 2006; } \\
\text { Landa et al., 2012; Ozonoff et al., } 2008 \text { [58,231-235] }\end{array}$ & Baranek, 1999; Landa et al., 2013 [9,236] \\
\hline & ADHD & Fliers et al., 2009; Rommelse et al., 2007 [100,112] & Karatekin et al., 2003; Kroes et al., 2002 [107,237] \\
\hline & Dyslexia & Viholainen et al., 2002; Viholainen et al., 2006 [238,239] & $\begin{array}{l}\text { Cannon et al., 1999; Clarke et al., 2011; Murray et al., } \\
\text { 2006; Rosso et al., 2000; Schiffman et al., 2009; Walker } \\
\text { and Lewine, 1990; Watkins et al., } 1988 \text { [240-246] }\end{array}$ \\
\hline $\begin{array}{l}\text { Psychiatric } \\
\text { disorders }\end{array}$ & Schizophrenia & $\begin{array}{l}\text { Aksoy-Poyraz et al., 2011; Blanchard et al., 2010; Chan } \\
\text { et al., 2010; Chang and Lenzenweger, 2001, 2005; Chen } \\
\text { et al., 2000; Compton et al., 2007; Egan et al., 2001; Fish, } \\
\text { 1976; Fish and Dixon, 1978, Fish and Hagin, 1973; } \\
\text { Gschwandtner et al., 2006; Ismail et al., 1998; Koning et al., } \\
\text { 2011; Marcus et al., 1993; Mechri et al., 2009; Mechri et al., } \\
\text { 2010; Mittal et al.,2007; Mittal et al., 2008; Neumann and } \\
\text { Walker, 2003; Picchioni et al., 2006; Prasad et al., 2009; } \\
\text { Rieder and Nichols, 1979; Walker et al., 1999; Yazici et al., } \\
2002 \text { [247] [248-250] [251-253] [254] [163-166,171,247-265] }\end{array}$ & \\
\hline \multirow{5}{*}{$\begin{array}{l}\text { Affective } \\
\text { disorders }\end{array}$} & Depression & Harjan, 1989 [266] & Pine et al., 1993; Shaffer et al., $1985[267,268]$ \\
\hline & Anxiety & Turner et al., 2005 [269] & Shaffer et al., 1985; Sigurdsson et al., 2002 [268,270] \\
\hline & Bipolar & & Sigurdsson et al., 1999) [271] \\
\hline & OCD & Peng et al., 2012 [184] & Grisham et al., 2011 [272] \\
\hline & PTSD & Gurvits et al., 2006 [129] & \\
\hline \multirow{2}{*}{$\begin{array}{l}\text { Degenerative } \\
\text { disorders }\end{array}$} & Aging & & Inzitari et al., 2006 [273] \\
\hline & $\begin{array}{l}\text { Alzheimer } \\
\text { disease }\end{array}$ & $\begin{array}{l}\text { Aggarwal et al., 2006; Rolland et al., 2009; Scarmeas et al., } \\
2005[194,274,275]\end{array}$ & \\
\hline
\end{tabular}

${ }^{\mathrm{a} A D H D}$, attention-deficit/hyperactivity disorder; NSS, neurological soft sign; OCD, obsessive-compulsive disorder; PTSD, posttraumatic stress disorder.

irregularities included within the group of secondary symptoms--such as self-regulation and eating and sleeping difficulties--have also been associated with a wide range of disorders. Although a systematic review of these symptoms is still lacking, they seem to follow a similar pattern (see [4] for examples). Taken together, the facts that secondary symptoms are widespread and that they are even associated with the extreme end of the healthy subclinical spectrum indicate a need for a reexamination of their possible contribution to understanding the pathways to psychopathology. Next, we suggest that the nonspecific nature of these secondary symptoms, which may have led to their being overlooked by clinicians and researchers, may actually be an advantage in the eyes of the emerging field of systems neuroscience.

\section{Explaining the pattern of occurrence of sensory and motor secondary symptoms within a systems neuroscience framework \\ Outlining the systems neuroscience framework}

Driven by methodological advances concerned with the study and analysis of complex networks in the brain, the exciting new field of systems neuroscience offers a novel perspective on ways to examine the brain, both in health and in psychopathology [5,297]. Systems neuroscientists use graph theoretical tools to assess various network metrics ${ }^{1}$ [1] from a large body of functional and structural connectivity data obtained from diffusion tensor imaging (DTI), functional magnetic resonance imaging (fMRI), magnetoencephalography (MEG) and electroencephalography (EEG) studies. The network metrics obtained from these data allow for the examination of normal and psychopathological brain states within a framework of global network structures (see, [5], for example), thereby indicating the efficiency of information transfer across the whole network and the ability of large-scale networks within the brain to switch between engaged and disengaged modes of function.

For example, converging evidence indicates that healthy brains are characterized by small-world architecture [298,299], which describes a configuration in which most nodes are not neighbors, but can be reached from every other node by a small number of steps. Such an architecture enables a balance between local and global structural characteristics and thus an optimal balance between segregation and integration, which is essential for high synchronicity and fast information transmission in a complex network [300].

Furthermore, it is believed that the construction of brain networks (as well as most biological networks) in small-world architecture may reflect an evolutionary advantage. One possibility is that small-world networks are more robust to perturbations than other network 
Table 4 Sensory and/or motor irregularities are associated with negative symptoms in healthy individuals

\begin{tabular}{ll}
\hline Signs of psychopathology & References \\
\hline Anxiety and depression symptoms & Bart, 2009; Kogan, 2008; Lane, 2010; Kinnealey, 1999; Engel-Yeger, \\
& 2011; Liss, 2008; Liss, 2005; Goldsmith, 2006; Piek, 2008; Pearsall-Jones, \\
& 2011; Piek, 2010; Kinnealey, 1999 [278-288] \\
Alexithymia and autistic characteristics & Liss, 2008; Robertson, 2013 [287,289] \\
Social phobia symptoms & Neal, 2002 [290] \\
Avoidant and borderline personality traits & Meyer, 2005; Meyer, 2000 [291,292] \\
Psychiatric symptoms & Ben-Sasson, 2009; Gouze, 2009; Stansfeld, 1985 [293-295] \\
\hline
\end{tabular}

architectures [301,302]. This robustness is supported by global network mechanisms [302] that limit the effects of potentially disruptive perturbations [301-304]. For example, the high modularity and degeneracy characteristics of small-world networks enables the insulation of subsystems that are functionally connected to each other from spreading perturbations (due to high modularity) and supports functional homeostasis even in the face of large structural variation in structure (due to the existence of many degenerate pathways) [305]. The inhibitory connections spread throughout the network play an important role in maintaining dynamic balance, whereas self-organizing regulatory mechanisms support functional homeostasis [306]. All of these network mechanisms maintain the remarkable capacity of the brain to withstand a wide range of perturbations in the course of injury and disease [302]. Thus, abnormalities in network metrics can result in general network failure, which affects network robustness as well as efficient information transfer, and can cause deficits in the access, engagement and disengagement of large-scale networks supporting cognition and behavior [302,307].

\section{Aberrations in network metrics follow a similar pattern of occurrence}

Using network analytical methods, researchers who have conducted empirical and theoretical studies have found that aberrations in various network metrics are a telltale sign of significant global deficits in brain organization [5] and that psychopathology is related to dysfunctional brain organization [302,308]. Convergent anatomical and functional evidence from a wide range of methodologies and from many different psychopathological states indicates that the disruption of global network connectivity, as indicated by abnormalities in various network metrics, is associated with disturbances in cognition and behavior as well as with signs of psychopathology [309-312].

A range of neurodevelopmental disorders have already been described in terms of aberrant network measures. In an EEG study comparing children with autism to healthy controls, children with autism showed a loss of small-world architecture, characterized by a significantly increased path length and reduced clustering [313,314]. Similar findings were also demonstrated for high-functioning adults with autism and for those with Asperger syndrome [315,316]. Another neurodevelopmental disorder that has been studied using a network approach is ADHD. Using resting-state fMRI data, several studies have revealed alterations in small-world architecture, characterized by increased local network efficiencies and decreases in global network efficiencies, in both children and adults with ADHD [317-319].

Schizophrenia, a psychiatric disorder that is considered to be neurodevelopmental in origin [6], has also been studied extensively using network analytical tools [320-322]. For example, a comparison of structural data from schizophrenia patients and healthy controls indicated a loss of small-world architecture as measured by a significantly lower clustering coefficient, longer characteristic path length and dysfunctional central hubs [320,323].

Abnormalities in network metrics were also reported for affective disorders as well as for neurodegenerative disorders and aging. For example, aberrant small-world architecture was found for drug-naïve, first-episode major depression patients [324] and for patients with OCD [325]. Abnormalities in network metrics were also reported when functional connectivity data from patients with AD [326-329], dementia [330] and traumatic brain injury [331] were compared to those from controls. Interestingly, aberrations in network metrics were also observed in healthy elders compared to healthy younger adults [332,333]. Taken together, these studies suggest that network aberrations are a general characteristic of psychopathologies without regard to the causes leading to the psychopathology.

Perhaps even more interesting is the fact that disruptions in network metrics seem to occur even before the full-blown disorder is evident [334-337]. This is most obvious in AD and schizophrenia, which have been studied extensively in this respect. For example, Yao et al. [334] measured network parameters in patients with $\mathrm{AD}$, individuals with mild cognitive impairments (MCIs) and healthy age-matched controls. The longest absolute path length and the greatest clustering coefficient were found 
in patients with $\mathrm{AD}$, which indicates that the small-world organization of the cortical network was the least optimal in $\mathrm{AD}$. The small-world measures of the MCI network exhibited intermediate values between $\mathrm{AD}$ and the normal aging controls. Given that MCI is a transitional stage between normal aging and $\mathrm{AD}$ [334], these findings, as well as those reported in other studies [338-341], suggest that network aberrations are evident in at-risk individuals much before the full-blown AD symptoms appear [334].

With regard to schizophrenia, Dazzan et al. [342] obtained MRI data from 102 individuals considered to be at a very high risk for schizophrenia and followed them for one year. Those who developed schizophrenia or other forms of psychosis had more volumetric abnormalities in distributed brain areas at the time of the MRI scan than those who did not develop a form of psychosis. That risk for schizophrenia is associated with aberrant brain architecture is further supported by additional studies indicating pervasive brain anatomical abnormalities in individuals at high risk for schizophrenia [343,344], even as early as neonatal stages [345]. Shi et $a l$. found that neonates at genetic risk for schizophrenia tended to have more aberrant metrics--such as globally lower efficiency and longer connection distance--than healthy controls, which indicates a less optimal smallworld structures [345].

Further support that network aberrations predate the onset of a psychopathology is provided by studies demonstrating that healthy individuals with autistic traits [346] and healthy individuals with familial risk for ADHD [347] display more network abnormalities compared to healthy individuals with no risk for psychopathology. Dennis et al. [348] showed that structural brain networks of healthy individuals (measured with DTI) carrying one of the known autism risk genes (CNTNAP2) exhibited altered structural connectivity that was reflected in aberrant path length, small-world structure and global efficiency as compared to non-at-risk individuals.

To summarize, similarly to the case of the secondary symptoms reviewed above, network aberrations seem to accompany many brain pathologies and appear in at-risk individuals even before a psychopathology is diagnosed. Furthermore, they seem to be predictive in nature. As mentioned above, abnormalities in global network metrics are related to the loss of the network's robustness and to an increase in vulnerability. In the next section, we suggest that secondary symptoms are linked to network aberrations and thus to brain vulnerability.

\section{Secondary symptoms as indicators of network vulnerability} Central to the framework developed herein is the observation that although sensory and/or motor secondary symptoms and network aberrations come from different levels of description-one at the behavioral level and the other at the network level-they display similar patterns of occurrence. They are both found across psychopathologies, before psychopathology emerges, and seem to have some predictive capability. Both theoretical and empirical evidence suggests that they may indeed be related.

On a theoretical level, the relation between secondary symptoms and network aberrations can be supported by a deeper understanding of the consequences of the loss of small-world architecture and abnormalities in network metrics. As mentioned above, small-world architecture enables greater robustness to perturbations, as well as more efficient information transfer and integration throughout the network. Moreover, the architecture of small-world networks gives rise to global network mechanisms that ensure the maintenance of dynamic balance. Thus, network failure leads not only to less robustness to perturbations but also to less efficient information transfer throughout the network, as well as to the disruption of mechanisms in charge of maintaining dynamic balance [302]. As a result, network failure should affect general network function, including the most basic input, output and regulation processes [302]. Thus, irregularities in sensory, motor and regulatory processes can be viewed as arising together with the loss of robustness due to network failure. In other words, the same network abnormalities that lead to loss of robustness can also lead to abnormalities in basic processes (that is, secondary symptoms).

Empirically, this proposed relation between secondary symptoms and network aberrations is supported by a recent set of experiments demonstrating that sensory and motor secondary symptoms are associated with structural brain irregularities. Dazzan et al. investigated NSSs in 43 healthy individuals using high-resolution MRI and voxel-based methods of image analysis [349]. They found that higher rates of NSSs were associated with a reduction in the size of the inferior frontal gyrus, the middle and superior temporal gyrus, and the anterior cingulate gyrus. Several other works have recently found a strong association between the occurrence of NSSs in patients with schizophrenia and structural abnormalities in subcortical brain morphology [350-354]; cerebellothalamo-prefrontal networks [355]; the corpus callosum [356]; and prefrontal, temporal and cerebellar structures [356-358]. Signs of sensory integration deficits have been associated with volume reduction in the cerebral cortex, including the precentral, superior and middle temporal, and lingual gyri [354]. In a longitudinal study, Kong et al. [359] investigated the cerebral correlates of persisting NSSs in first-episode patients with schizophrenia. They found that patients with a greater number of persistent neurological signs not only showed a less favorable outcome after one year (although differences did not reach significance) but also had significantly more structural 
abnormalities, which indicated a larger number of progressive cerebral changes. Taken together, these observations suggest that sensory and/or motor abnormalities represent clinical indicators of perturbed connectivity that underlies psychopathology $[349,353,354,360,361]$.

Thus, network theory suggests that loss of network robustness can arise together with irregularities in basic processes due to global network failure [302]. In addition, structural evidence suggests that sensory and/or motor abnormalities represent clinical indicators of abnormalities in brain architecture [349-361]. We thus suggest a novel integration between clinical observations and systems neuroscience that can explain the similarities between the patterns of occurrence of sensory and/or motor abnormalities and network aberrations. Within this framework, we propose that sensory and motor secondary symptoms reflect irregularities in basic processes arising because of network irregularities and are therefore indicators of vulnerable brain networks. In other words, they are a behavioral marker for a brain that is already in a psychopathological state or has the potential to develop a psychopathology under certain conditions.

The last part of our proposition suggests that prevalent appearance of secondary symptoms has a predictive nature. Thus, it can serve as a marker for individuals in whom psychopathology is not evident but has the potential to evolve. This is supported by many levels of evidence that we have referred to in this review, namely, the following: (1) that sensory and/or motor abnormalities appear in healthy individuals who are considered at risk for psychopathology (Table 3), (2) that sensory and/or motor abnormalities appear in healthy individuals not considered at risk for psychopathology but who display more negative symptoms than the average healthy population (Table 4), (3) that higher rates of NSSs in healthy people are associated with structural abnormalities [349] and (4) that healthy people at risk for psychopathology display network abnormalities.

\section{Discussion}

In this review, we emphasize the underlying pattern of occurrence of abnormalities in sensory and motor processes that seem to appear during states of psychopathology, before the psychopathology is evident and when there is a propensity to develop a psychopathology. Furthermore, our review demonstrates that even in healthy, undiagnosed individuals at no apparent risk for psychopathology, deviations from the norm in basic processes are correlated with more negative symptoms than those found in the average healthy population.

In addition, we show that abnormalities in network metrics associated with psychopathology exhibit a pattern of occurrence similar to that of secondary symptoms. We offer a novel integration between clinical observations and systems neuroscience to try to gain an understanding of the meaning of this pattern. This synthesis yielded a proposition that abnormalities in sensory and motor processes can be indications of a vulnerable brain (that is, a brain that has a higher probability of developing psychopathology following extreme circumstances).

Importantly, herein we focus only on a subset of possible secondary symptoms (sensory and/or motor). Although a similar systematic review of other secondary symptoms, such as sleeping, eating and self-regulation abnormalities, is lacking, a nonsystematic review that has been performed suggests that their pattern of appearance in relation to psychopathology resembles that of the sensory and/or motor secondary symptoms [4]. This similarity in patterns suggests that there are other indicators of brain vulnerability in addition to the sensory and/or motor symptoms reviewed herein.

The framework outlined herein supports the emerging theoretical approach that calls for a paradigm shift in the way psychopathologies are viewed, diagnosed and treated [3-5]. According to this approach, the current trend-in which syndromes are compartmentalized and viewed as exclusive and separable from each other and in which emphasis is placed on finding early markers that will predict specific disorders-is misguided [3]. The fact that many symptoms are shared across psychopathologies $[3,5]$ and that disorders often appear together suggests that many disorders (for example, ASD and ADHD) are actually representations of different aspects of the same underlying abnormality (for example, aberrations in global networks) [3,362]. Thus, symptoms that appear across disorders "should be considered markers for the (very likely) presence of a neurodevelopmental disorder that (very likely) will continue to cause symptoms long after their clinical surfacing" [3]. In accordance with this recent approach, our framework suggests that secondary symptoms, such as sensory and/or motor abnormalities, represent an underlying potential (due to network vulnerability) to develop psychopathology. The prevalence and severity of secondary symptoms may indicate the level of this vulnerability [363].

Whether this potential to develop psychopathology will be realized and how it will be expressed depend both on the "level of vulnerability" of the underlying network and on the existence, nature and timing of a trigger that can shift the system from healthy to psychopathological function. For example, a trigger can be the abnormal anatomical or synaptic changes that occur during powerful developmental or degenerative processes. Extreme circumstances can also serve as triggers (for example, stressful life adversities, chemical stressors or brain hemorrhages). Indeed, the interaction between developmental aberrations and external stressors is exemplified in schizophrenia. Growing evidence indicates that schizophrenia is a developmental 
disorder (see, for example, [6]). However, it usually erupts only during the stressful period of late adolescence and early adulthood, when young adults leave their parents' home and become independent [364]. The integrative framework presented herein emphasizes the need to better understand the interaction between the prevalence and severity of secondary signs, as well as the timing and nature of perturbations that can trigger the development of a psychopathology.

Several important clinical implications, relating to both early detection and intervention, arise from this framework. This review gathers an extensive body of supportive evidence showing that the appearance of nonspecific secondary symptoms, as well as nonspecific metric aberrations, precedes the development of specific psychopathologies. Early detection of vulnerability may therefore contribute to efforts directed at finding early markers of psychopathology $[3,4]$. Further research is needed to directly assess the clinical usefulness of secondary symptoms as predictors of psychopathology.

Regarding implications for interventions, it is possible that, once secondary symptoms are detected, an intervention could reduce vulnerability and prevent or curtail the development of psychopathology. Interestingly, preliminary evidence suggests that interventions targeting basic processes associated with secondary symptoms (for example, sensory, motor or sleep) seem to alleviate vulnerability in preterm infants and in individuals already diagnosed with a psychopathology (see, for example, [365-370]). These clinical implications suggest that, when viewed within the framework presented herein, secondary symptoms can provide important information that can guide clinical diagnosis and treatment.

\section{Conclusion}

The intent of this review is to attract attention to the nonspecific characteristics of psychopathologies and to demonstrate that, within the systems neuroscience framework, these characteristics may hold important information that can advance the theoretical and clinical understanding of psychopathologies. The direct evidence for a relation between behavioral secondary symptoms and network aberrations and vulnerability, as well as its clinical usefulness, is limited and requires substantial research. We hope the integrative framework outlined herein will stimulate work that aims to increase understanding of this relation further and to advance our understanding of the common mechanisms underlying disorders and how they can be used for prevention, diagnosis and treatment of disorders.

\section{Endnote}

${ }^{1}$ Network metrics include measures of local connectivity levels (such as the clustering and modularity of various nodes in the network), measures of global integration (such as the average path length between two nodes, which is indicative of how efficiently the network is connected) and measures of the importance of specific hub nodes (such as the centrality of specific nodes). Another example of a network metric is how much the brain adheres to a global network architecture, called a "small world network," that reflects high clustering, a short path length and the formation of densely connected hubs [298].

\section{Abbreviations}

AD: Alzheimer disease; ADHD: Attention-deficit/hyperactivity disorder; ASD: Autism spectrum disorder; DTI: Diffusion tensor imaging;

EEG: Electroencephalography; fMRI: Functional magnetic resonance imaging; MCl: Mild cognitive impairments; MEG: Magnetoencephalography NSS: Neurological soft sign; OCD: Obsessive-compulsive disorder; PTSD: Posttraumatic stress disorder.

\section{Competing interests}

The authors declare that they have no competing interests.

\section{Authors' contributions}

NVL, YG and MD participated equally in the review process and in the manuscript preparation process. All authors read and approved the final manuscript.

\section{Acknowledgments}

We gratefully acknowledge Elisha Moses for his support and encouragement. We also wish to thank Hilan Navot and Anna Wexler for their assistance with the manuscript. Finally, we wish to acknowledge the many therapists and clinicians working with individuals with difficulties from whose wisdom and knowledge we have been inspired.

\section{Author details}

${ }^{1}$ Interdisciplinary Center (IDC), Sagol Unit for Applied Neuroscience, School of Psychology, POB 167, Herzliya 46150, Israel. ${ }^{2}$ Tel Aviv Maccabi Healthcare Services, 27 Hamered St., Tel Aviv 68125, Israel.

Received: 13 February 2013 Accepted: 4 September 2013

Published: 24 September 2013

\section{References}

1. DeGangi GA, Breinbauer C, Roosevelt JD, Porges S, Greenspan S: Prediction of childhood problems at three years in children experiencing disorders of regulation during infancy. Infant Ment Health J 2000, 21:156-175.

2. Chan RCK, Wang Y, Wang L, Chen EYH, Manschreck TC, Li ZJ, Yu X, Gong QY: Neurological soft signs and their relationships to neurocognitive functions: a re-visit with the structural equation modeling design. PLoS One 2009, 4:e8469.

3. Gillberg C: The ESSENCE in child psychiatry: Early Symptomatic Syndromes Eliciting Neurodevelopmental Clinical Examinations. Res Dev Disabil 2010, 31:1543-1551.

4. Levit-Binnun N, Golland Y: Finding behavioral and network indicators of brain vulnerability. Front Hum Neurosci 2012, 6:10.

5. Menon V: Large-scale brain networks and psychopathology: a unifying triple network model. Trends Cogn Sci 2011, 15:483-506.

6. Gilmore JH: Understanding what causes schizophrenia: a developmental perspective. Am J Psychiatry 2010, 167:8-10.

7. Adamson A, O'Hare A, Graham C: Impairments in sensory modulation in children with autistic spectrum disorder. Br J Occup Ther 2006, 69:357-364

8. Adrien JL, Ornitz E, Barthelemy C, Sauvage D, Lelord G: The presence or absence of certain behaviors associated with infantile autism in severely retarded autistic and nonautistic retarded children and very young normal children. J Autism Dev Disord 1987, 17:407-416.

9. Baranek GT: Autism during infancy: a retrospective video analysis of sensory-motor and social behaviors at 9-12 months of age. J Autism Dev Disord 1999, 29:213-224. 
10. Baranek GT, Boyd BA, Poe MD, David FJ, Watson LR: Hyperresponsive sensory patterns in young children with autism, developmental delay, and typical development. Am J Ment Retard 2007, 112:233-245.

11. Baranek GT, David FJ, Poe MD, Stone WL, Watson LR: Sensory Experiences Questionnaire: discriminating sensory features in young children with autism, developmental delays, and typical development. J Child Psychol Psychiatry 2006, 47:591-601.

12. Baranek GT, Watson LR, Boyd BA, Poe MD, David FJ, McGuire L: Hyporesponsiveness to social and nonsocial sensory stimuli in children with autism, children with developmental delays, and typically developing children. Dev Psychopathol 2013, 25:307-320.

13. Ben-Sasson A, Cermak SA, Orsmond Gl, Tager-Flusberg H, Carter AS, Kadlec $M B$, Dunn W: Extreme sensory modulation behaviors in toddlers with autism spectrum disorders. Am J Occup Ther 2007, 61:584-592.

14. Blakemore SJ, Tavassoli T, Calò S, Thomas RM, Catmur C, Frith U, Haggard P: Tactile sensitivity in Asperger syndrome. Brain Cogn 2006, 61:5-13.

15. Blanche El, Reinoso G, Chang MC, Bodison S: Proprioceptive processing difficulties among children with autism spectrum disorders and developmental disabilities. Am J Occup Ther 2012, 66:621-624.

16. Cascio C, McGlone F, Folger S, Tannan V, Baranek G, Pelphrey KA, Essick G: Tactile perception in adults with autism: a multidimensional psychophysical study. J Autism Dev Disord 2008, 38:127-137.

17. Crane L, Goddard L, Pring L: Sensory processing in adults with autism spectrum disorders. Autism 2009, 13:215-228.

18. Dickie VA, Baranek GT, Schultz B, Watson LR, McComish CS: Parent reports of sensory experiences of preschool children with and without autism: a qualitative study. Am J Occup Ther 2009, 63:172-181.

19. Dunn W, Myles BS, Orr S: Sensory processing issues associated with Asperger syndrome: a preliminary investigation. Am J Occup Ther 2002, 56:97-102

20. Hilton CL, Harper JD, Kueker RH, Lang AR, Abbacchi AM, Todorov A, LaVesser PD: Sensory responsiveness as a predictor of social severity in children with high functioning autism spectrum disorders. J Autism Dev Disord 2010, 40:937-945.

21. Hochhauser M, Engel-Yeger B: Sensory processing abilities and their relation to participation in leisure activities among children with highfunctioning autism spectrum disorder (HFASD). Res Autism Spectr Disord 2010, 4:746-754

22. Kern JK, Garver CR, Carmody T, Andrews AA, Mehta JA, Trivedi MH: Examining sensory modulation in individuals with autism as compared to community controls. Res Autism Spectr Disord 2008, 2:85-94.

23. Kern JK, Garver CR, Carmody T, Andrews AA, Trivedi MH, Mehta JA Examining sensory quadrants in autism. Res Autism Spectr Disord 2007, 1:185-193.

24. Kern JK, Garver CR, Grannemann BD, Trivedi MH, Carmody T, Andrews AA, Mehta JA: Response to vestibular sensory events in autism. Res Autism Spectr Disord 2007, 1:67-74

25. Kern JK, Trivedi MH, Garver CR, Grannemann BD, Andrews AA, Savla JS, Johnson DG, Mehta JA, Schroeder JL: The pattern of sensory processing abnormalities in autism. Autism 2006, 10:480-494.

26. Kern JK, Trivedi MH, Grannemann BD, Garver CR, Johnson DG, Andrews AA Savla JS, Mehta JA, Schroeder JL: Sensory correlations in autism. Autism $2007,11: 123-134$

27. Khalfa S, Bruneau N, Rogé B, Georgieff N, Veuillet E, Adrien JL, Barthélémy C, Collet L: Increased perception of loudness in autism. Hear Res 2004, 198:87-92.

28. Kientz MA, Dunn W: A comparison of the performance of children with and without autism on the Sensory Profile. Am J Occup Ther 1997, 51:530-537.

29. Kwakye LD, Foss-Feig JH, Cascio CJ, Stone WL, Wallace MT: Altered auditory and multisensory temporal processing in autism spectrum disorders. Front Integr Neurosci 2011, 4:129.

30. Leekam SR, Nieto C, Libby SJ, Wing L, Gould J: Describing the sensory abnormalities of children and adults with autism. J Autism Dev Disord 2007, 37:894-910

31. O'Brien J, Tsermentseli S, Cummins O, Happé F, Heaton P, Spencer J: Discriminating children with autism from children with learning difficulties with an adaptation of the Short Sensory Profile. Early Child Dev Care 2009, 179:383-394.

32. Reynolds S, Lane SJ, Thacker L: Sensory processing, physiological stress, and sleep behaviors in children with and without autism spectrum disorders. OTJR (Thorofare N J) 2012, 32:246-257.
33. Rogers SJ, Hepburn S, Wehner E: Parent reports of sensory symptoms in toddlers with autism and those with other developmental disorders. J Autism Dev Disord 2003, 33:631-642.

34. Siaperas $P$, Ring HA, McAllister CJ, Henderson S, Barnett A, Watson P, Holland AJ: Atypical movement performance and sensory integration in Asperger's syndrome. J Autism Dev Disord 2012, 42:718-725.

35. Tavassoli T, Baron-Cohen S: Taste identification in adults with autism spectrum conditions. J Autism Dev Disord 2012, 42:1419-1424.

36. Tomchek SD, Dunn W: Sensory processing in children with and without autism: a comparative study using the Short Sensory Profile. Am J Occup Ther 2007, 61:190-200

37. Watling RL, Deitz J, White O: Comparison of Sensory Profile scores of young children with and without autism spectrum disorders. Am J Occup Ther 2001, 55:416-423.

38. Woodard CR, Goodwin MS, Zelazo PR, Aube D, Scrimgeour M, Ostholthoff T, Brickley M: A comparison of autonomic, behavioral, and parent-report measures of sensory sensitivity in young children with autism. Res Autism Spectr Disord 2012, 6:1234-1246.

39. Weimer AK, Schatz AM, Lincoln A, Ballantyne AO, Trauner DA: "Motor" impairment in Asperger syndrome: evidence for a deficit in proprioception. J Dev Behav Pediatr 2001, 22:92-101.

40. Cheung PPP, Siu AMH: A comparison of patterns of sensory processing in children with and without developmental disabilities. Res Dev Disabil 2009, 30:1468-1480.

41. Reynolds S, Bendixen RM, Lawrence T, Lane SJ: A pilot study examining activity participation, sensory responsiveness, and competence in children with high functioning autism spectrum disorder. J Autism Dev Disord 2011, 41:1496-1506.

42. Fuentes $\mathrm{CT}$, Mostofsky SH, Bastian AJ: No proprioceptive deficits in autism despite movement-related sensory and execution impairments. J Autism Dev Disord 2011, 41:1352-1361.

43. Güçlü B, Tanidir C, Mukaddes NM, Ünal F: Tactile sensitivity of normal and autistic children. Somatosens Mot Res 2007, 24:21-33.

44. Jones CRG, Happé F, Baird G, Simonoff E, Marsden AJS, Tregay J, Phillips RJ, Goswami U, Thomson JM, Charman T: Auditory discrimination and auditory sensory behaviours in autism spectrum disorders. Neuropsychologia 2009, 47:2850-2858.

45. Tavassoli T, Baron-Cohen S: Olfactory detection thresholds and adaptation in adults with autism spectrum condition. J Autism Dev Disord 2012, 42:905-909.

46. Lopata C, Hamm EM, Volker MA, Sowinski JE: Motor and visuomotor skills of children with Asperger's disorder: preliminary findings. Percept Mot Skills 2007, 104:1183-1192.

47. Pan $\mathrm{CY}$, Tsai $\mathrm{CL}$, Chu CH: Fundamental movement skills in children diagnosed with autism spectrum disorders and attention deficit hyperactivity disorder. J Autism Dev Disord 2009, 39:1694-1705

48. Papadopoulos N, McGinley J, Tonge B, Bradshaw J, Saunders K, Murphy A, Rinehart N: Motor proficiency and emotional/behavioural disturbance in autism and Asperger's disorder: another piece of the neurological puzzle? Autism 2012, 16:627-640

49. Sahlander C, Mattsson M, Bejerot S: Motor function in adults with Asperger's disorder: a comparative study. Physiother Theory Pract 2008, 24:73-81.

50. Travers B, Powell $P$, Klinger $L$, Klinger M: Motor difficulties in autism spectrum disorder: linking symptom severity and postural stability. J Autism Dev Disord 2013, 43:1568-1583.

51. Whyatt $C P$, Craig CM: Motor skills in children aged 7-10 years, diagnosed with autism spectrum disorder. J Autism Dev Disord 2012, 42:1799-1809.

52. Dewrang P, Sandberg AD: Parental retrospective assessment of development and behavior in Asperger syndrome during the first 2 years of life. Res Autism Spectr Disord 2010, 4:461-473.

53. Esposito G, Venuti P: Analysis of toddlers' gait after six months of independent walking to identify autism: a preliminary study. Percept Mot Skills 2008, 106:259-269.

54. Freitag CM, Kleser C, Schneider M, von Gontard A: Quantitative assessment of neuromotor function in adolescents with high functioning autism and Asperger syndrome. J Autism Dev Disord 2007, 37:948-959.

55. Gernsbacher MA, Sauer EA, Geye HM, Schweigert EK, Goldsmith HH: Infant and toddler oral- and manual-motor skills predict later speech fluency in autism. J Child Psychology Psychiatr 2008, 49:43-50 
56. Hilton C, Wente L, LaVesser P, Ito M, Reed C, Herzberg G: Relationship between motor skill impairment and severity in children with Asperger syndrome. Res Autism Spectr Disord 2007, 1:339-349.

57. Hilton $\mathrm{CL}$, Zhang Y, Whilte MR, Klohr CL, Constantino J: Motor impairment in sibling pairs concordant and discordant for autism spectrum disorders. Autism 2012, 16:430-441.

58. Ozonoff S, Young GS, Goldring S, Greiss-Hess L, Herrera AM, Steele J, Macari S, Hepburn S, Rogers SJ: Gross motor development, movement abnormalities, and early identification of autism. J Autism Dev Disord 2008, 38:644-656.

59. De Jong M, Punt M, De Groot E, Minderaa RB, Hadders-Algra M: Minor neurological dysfunction in children with autism spectrum disorder. Dev Med Child Neurol 2011, 53:641-646.

60. Jansiewicz EM, Goldberg MC, Newschaffer CJ, Denckla MB, Landa R, Mostofsky SH: Motor signs distinguish children with high functioning autism and Asperger's syndrome from controls. J Autism Dev Disord 2006, 36:613-621.

61. Jones V, Prior M: Motor imitation abilities and neurological signs in autistic children. J Autism Dev Disord 1985, 15:37-46.

62. Tani $P$, Lindberg N, Appelberg B, Nieminen-von Wendt $T$, von Wendt $L$, Porkka-Heiskanen T: Clinical neurological abnormalities in young adults with Asperger syndrome. Psychiatry Clin Neurosci 2006, 60:253-255.

63. Taal MN, Rietman AB, Meulen SVD, Schipper M, Dejonckere PH: Children with specific language impairment show difficulties in sensory modulation. Logoped Phoniatr Vocol 2013, 38:70-78.

64. Finlay JCS, MCPhillips M: Comorbid motor deficits in a clinical sample of children with specific language impairment. Res Dev Disabil 2013, 34:2533-2542.

65. Owen SE, McKinlay IA: Motor difficulties in children with developmental disorders of speech and language. Child Care Health Dev 1997, 23:315-325.

66. Zelaznik HN, Goffman L: Generalized motor abilities and timing behavior in children with specific language impairment. J Speech Lang Hear Res 2010, 53:383-393.

67. Chuang YC, Hsu CY, Chiu NC, Lin SP, Tzang RF, Yang CC: Other impairment associated with developmental language delay in preschool-aged children. J Child Neurol 2011, 26:714-717.

68. Müürsepp I, Ereline J, Gapeyeva H, Pääsuke M: Motor performance in 5year-old preschool children with developmental speech and language disorders. Acta Paediatr 2009, 98:1334-1338.

69. Fraser J, Goswami U, Conti-Ramsden G: Dyslexia and specific language impairment: the role of phonology and auditory processing. Sci Stud Read 2010, 14:8-29.

70. Georgiou GK, Papadopoulos TC, Zarouna E, Parrila R: Are auditory and visual processing deficits related to developmental dyslexia? Dyslexia 2012, 18:110-129.

71. Heiervang E, Stevenson J, Hugdahl K: Auditory processing in children with dyslexia. J Child Psychol Psychiatry 2002, 43:931-938.

72. White S, Frith U, Milne E, Rosen S, Swettenham J, Ramus F: A double dissociation between sensorimotor impairments and reading disability: a comparison of autistic and dyslexic children. Cogn Neuropsychol 2006, 23:748-761

73. Wright $\mathrm{CM}$, Conlon EG: Auditory and visual processing in children with dyslexia. Dev Neuropsychol 2009, 34:330-355.

74. Polatajko HJ: A critical look at vestibular dysfunction in learning-disabled children. Dev Med Child Neurol 1985, 27:283-292.

75. White S, Milne E, Rosen S, Hansen P, Swettenham J, Frith U, Ramus F: The role of sensorimotor impairments in dyslexia: a multiple case study of dyslexic children. Dev Sci 2006, 9:237-255. 265-269.

76. Brookes RL, Tinkler S, Nicolson Rl, Fawcett AJ: Striking the right balance: motor difficulties in children and adults with dyslexia. Dyslexia 2010 16:358-373.

77. Cinelli B, DePaepe JL: Dynamic balance of learning disabled and nondisabled children. Percept Mot Skills 1984, 58:243-245.

78. Kinnealey M: Tactile functions in learning-disabled and normal children: reliability and validity considerations. Occup Ther J Res 1989, 9:3-15.

79. Needle JL, Fawcett AJ, Nicolson RI: Balance and dyslexia: an investigation of adults' abilities. Eur J Cogn Psychol 2006, 18:909-936.

80. Getchell N, Pabreja P, Neeld K, Carrio V: Comparing children with and without dyslexia on the Movement Assessment Battery for Children and the Test of Gross Motor Development. Percept Mot Skills 2007, 105:207-214.

81. Nicolson Rl, Fawcett AJ: Comparison of deficits in cognitive and motor skills among children with dyslexia. Ann Dyslexia 1994, 44:147-164.
82. Bruininks $V L$, Bruininks $R H$ : Motor proficiency of learning disabled and nondisabled students. Percept Mot Skills 1977, 44:1131-1137.

83. Cermak SA, Trimble H, Coryell J, Drake C: Bilateral motor coordination in adolescents with and without learning disabilities. Phys Occup Ther Pediatr 1990, 10:5-18.

84. Durand M: Is there a fine motor skill deficit in nonverbal learning disabilities? Educ Child Psychol 2005, 22:90-99.

85. Haslum MN, Miles TR: Motor performance and dyslexia in a national cohort of 10-year-old children. Dyslexia 2007, 13:257-275.

86. Maloy CF, Sattler JM: Motor and cognitive proficiency of learning disabled and normal children. J Sch Psychol 1979, 17:213-218.

87. Pieters $\mathrm{S}$, Desoete $\mathrm{A}$, Roeyers $\mathrm{H}$, Vanderswalmen $\mathrm{R}$, Van Waelvelde $\mathrm{H}$ : Behind mathematical learning disabilities: What about visual perception and motor skills? Learn Individ Differ 2012, 22:498-504

88. Vuijk PJ, Hartman E, Mombarg R, Scherder E, Visscher C: Associations between academic and motor performance in a heterogeneous sample of children with learning disabilities. J Learn Disabil 2011, 44:276-282.

89. Westendorp M, Hartman E, Houwen S, Smith J, Visscher C: The relationship between gross motor skills and academic achievement in children with learning disabilities. Res Dev Disabil 2011, 32:2773-2779.

90. McPhillips M, Sheehy N: Prevalence of persistent primary reflexes and motor problems in children with reading difficulties. Dyslexia 2004 10:316-338

91. Trauner D, Wulfeck B, Tallal P, Hesselink J: Neurological and MRI profiles of children with developmental language impairment. Dev Med Child Neurol 2000, 42:470-475

92. Bröring T, Rommelse N, Sergeant J, Scherder E: Sex differences in tactile defensiveness in children with ADHD and their siblings. Dev Med Child Neurol 2008, 50:129-133.

93. Dunn W, Bennett D: Patterns of sensory processing in children with attention deficit hyperactivity disorder. OTJR (Thorofare N J) 2002, 22:4-15.

94. Engel-Yeger B, Ziv-On D: The relationship between sensory processing difficulties and leisure activity preference of children with different types of ADHD. Res Dev Disabil 2011, 32:1154-1162.

95. Lufi D, Tzischinsky O: The relationships between sensory modulation and sleep among adolescents with ADHD. J Atten Disord 2012. 10.1177/ 1087054712457036.

96. Romanos M, Renner TJ, Schecklmann M, Hummel B, Roos M, von Mering C, Pauli P, Reichmann H, Warnke A, Gerlach M: Improved odor sensitivity in attention-deficit/hyperactivity disorder. Biol Psychiatry 2008 64:938-940.

97. Miller $\amalg$, Nielsen DM, Schoen SA: Attention deficit hyperactivity disorder and sensory modulation disorder: a comparison of behavior and physiology. Res Dev Disabil 2012, 33:804-818.

98. Gomez R, Condon M: Central auditory processing ability in children with ADHD with and without learning disabilities. J Learn Dis 1999, 32:150-158.

99. Schlee G, Neubert T, Worenz A, Milani TL: Children with ADHD show no deficits in plantar foot sensitivity and static balance compared to healthy controls. Res Dev Disabil 2012, 33:1957-1963.

100. Fliers E, Vermeulen S, Rijsdijk F, Altink M, Buschgens C, Rommelse N, Faraone S, Sergeant J, Buitelaar J, Franke B: ADHD and poor motor performance from a family genetic perspective. J Am Acad Child Adolesc Psychiatry 2009, 48:25-34

101. Flapper BC, Houwen S, Schoemaker MM: Fine motor skills and effects of methylphenidate in children with attention-deficit-hyperactivity disorder and developmental coordination disorder. Dev Med Child Neurol 2006, 48:165-169.

102. Chan RCK, McAlonan GM, Yang B, Lin L, Shum D, Manschreck TC: Prevalence of neurological soft signs and their neuropsychological correlates in typically developing Chinese children and Chinese children with ADHD. Dev Neuropsychol 2010, 35:698-711.

103. Fliers EA, de Hoog MLA, Franke B, Faraone SV, Rommelse NNJ, Buitelaar JK der Sanden MWN-v: Actual motor performance and self-perceived motor competence in children with attention-deficit hyperactivity disorder compared with healthy siblings and peers. J Dev Behav Pediatr 2010, 31:35-40.

104. Goulardins JB, Marques JCB, Casella EB, Nascimento RO, Oliveira JA: Motor profile of children with attention deficit hyperactivity disorder, combined type. Res Dev Disabil 2013, 34:40-45.

105. Harvey W, Reid G, Grizenko N, Mbekou V, Ter-Stepanian M, Joober R: Fundamental movement skills and children with attention-deficit 
hyperactivity disorder: peer comparisons and stimulant effects. J Abnorm Child Psychol 2007, 35:871-882.

106. Klotz JM, Johnson MD, Wu SW, Isaacs KM, Gilbert DL: Relationship between reaction time variability and motor skill development in ADHD. Child Neuropsychol 2012, 18:576-585.

107. Karatekin C, Markiewicz SW, Siegel MA: A preliminary study of motor problems in children with attention-deficit/hyperactivity disorder. Percept Mot Skills 2003, 97:1267-1280.

108. Klimkeit El, Sheppard DM, Lee P, Bradshaw JL: Bimanual coordination deficits in attention deficit/hyperactivity disorder (ADHD). J Clin Exp Neuropsychol 2004, 26:999-1010.

109. Meyer A, Sagvolden T: Fine motor skills in South African children with symptoms of ADHD: influence of subtype, gender, age, and hand dominance. Behav Brain Funct 2006, 2:33.

110. Okuda PM, Pinheiro FH, Germano GD, Padula NA, Lourencetti MD, Santos LC, Capellini SA: Fine motor, sensory and perceptive function of students with attention deficit disorder with hyperactivity [in English and Portuguese]. J Soc Bras Fonoaudiol 2011, 23:351-357.

111. Piek JP, Pitcher TM, Hay DA: Motor coordination and kinaesthesis in boys with attention deficit-hyperactivity disorder. Dev Med Child Neurol 1999, 41:159-165.

112. Rommelse NNJ, Altink ME, Oosterlaan J, Buschgens CJM, Buitelaar J, De Sonneville LMJ, Sergeant JA: Motor control in children with ADHD and non-affected siblings: deficits most pronounced using the left hand. J Child Psychol Psychiatry 2007, 48:1071-1079.

113. Slaats-Willemse D, de Sonneville L, Swaab-Barneveld H, Buitelaar J: Motor flexibility problems as a marker for genetic susceptibility to attentiondeficit/hyperactivity disorder. Biol Psychiatry 2005, 58:233-238.

114. Kooistra L, Crawford S, Dewey D, Cantell M, Kaplan BJ: Motor correlates of ADHD: contribution of reading disability and oppositional defiant disorder. J Learn Disabil 2005, 38:195-206.

115. Lee IC, Chen YJ, Tsai CL: Kinematic performance of fine motor control in attention-deficit/hyperactivity disorder: the effects of comorbid developmental coordination disorder and core symptoms. Pediatr Int 2013, 55:24-29.

116. Polderman TJC, van Dongen J, Boomsma DI: The relation between ADHD symptoms and fine motor control: a genetic study. Child Neuropsychol 2011, 17:138-150.

117. Dickstein DP, Garvey M, Pradella AG, Greenstein DK, Sharp WS, Castellanos FX, Pine DS, Leibenluft E: Neurologic examination abnormalities in children with bipolar disorder or attention-deficit/hyperactivity disorder. Biol Psychiatry 2005, 58:517-524.

118. Ferrin $M$, Vance A: Examination of neurological subtle signs in ADHD as a clinical tool for the diagnosis and their relationship to spatial working memory. J Child Psychol Psychiatry 2012, 53:390-400.

119. Kristensen $\mathrm{H}$, Torgersen $\mathrm{S}$ : The association between avoidant personality traits and motor impairment in a population-based sample of 11-12-year-old children. J Pers Disord 2007, 21:87-97.

120. Skirbekk B, Hansen BH, Oerbeck B, Wentzel-Larsen T, Kristensen H: Motor impairment in children with anxiety disorders. Psychiatry Res 2012, 198:135-139.

121. Ekornås B, Lundervold AJ, Tjus T, Heimann M: Anxiety disorders in 8-11year-old children: motor skill performance and self-perception of competence. Scand J Psychol 2010, 51:271-277.

122. Jacob RG, Redfern MS, Furman JM: Space and motion discomfort and abnormal balance control in patients with anxiety disorders. J Neurol Neurosurg Psychiatry 2009, 80:74-78.

123. Erez O, Gordon CR, Sever J, Sadeh A, Mintz M: Balance dysfunction in childhood anxiety: findings and theoretical approach. J Anxiety Disord 2004, 18:341-356.

124. Farrow CV, Coulthard H: Relationships between sensory sensitivity, anxiety and selective eating in children. Appetite 2012, 58:842-846.

125. Hofmann SG, Bitran S: Sensory-processing sensitivity in social anxiety disorder: relationship to harm avoidance and diagnostic subtypes. J Anxiety Disord 2007, 21:944-954.

126. Hollander E, Weiller F, Cohen L, Kwon JH, DeCaria CM, Liebowitz MR, Stein DJ: Neurological soft signs in social phobia. Neuropsychiatry Neuropsychol Behav Neurol 1996, 9:182-185.

127. Gurvits TV, Gilbertson MW, Lasko NB, Tarhan AS, Simeon D, Macklin ML, Orr SP, Pitman RK: Neurologic soft signs in chronic posttraumatic stress disorder. Arch Gen Psychiatry 2000, 57:181-186.
128. Gurvits TV, Lasko NB, Schachter SC, Kuhne AA, Orr SP, Pitman RK: Neurological status of Vietnam veterans with chronic posttraumatic stress disorder. J Neuropsychiatry Clin Neurosci 1993, 5:183-188.

129. Gurvits TV, Metzger LJ, Lasko NB, Cannistraro PA, Tarhan AS, Gilbertson MW, Orr SP, Charbonneau AM, Wedig MM, Pitman RK: Subtle neurologic compromise as a vulnerability factor for combat-related posttraumatic stress disorder: results of a twin study. Arch Gen Psychiatry 2006, 63:571-576.

130. Gurvits TV, Carson MA, Metzger L, Croteau HB, Lasko NB, Orr SP, Pitman RK: Absence of selected neurological soft signs in Vietnam nurse veterans with post-traumatic stress disorder. Psychiatry Res 2002, 110:81-85.

131. Günther W, Günther R, Streck P, Römig H, Rödel A: Psychomotor disturbances in psychiatric patients as a possible basis for new attempts at differential diagnosis and therapy. III. Cross validation study on depressed patients: the psychotic motor syndrome as a possible state marker for endogenous depression. Eur Arch Psychiatry Neurol Sci 1988, 237:65-73.

132. Lohr JB, May T, Caligiuri MP: Quantitative assessment of motor abnormalities in untreated patients with major depressive disorder. $J$ Affect Disord 2013, 146:84-90.

133. Schwartz F, Carr A, Munich RL, Bartuch E, Lesser B, Rescigno D, Viegener B: Voluntary motor performance in psychotic disorders: a replication study. Psychol Rep 1990, 66:1223-1234.

134. Zhao Q, Ma YT, Lui SS, Liu WH, Xu T, Yu X, Tan SP, Wang ZR, Qu M, Wang Y, Huang J, Cheung EF, Dazzan P, Chan RC: Neurological soft signs discriminate schizophrenia from major depression but not bipolar disorder. Prog Neuropsychopharmacol Biol Psychiatry 2013, 43:72-78.

135. Boks MPM, Liddle PF, Burgerhof JGM, Knegtering R, van den Bosch RJ Neurological soft signs discriminating mood disorders from first episode schizophrenia. Acta Psychiatr Scand 2004, 110:29-35.

136. Manschreck TC, Ames D: Neurologic features and psychopathology in schizophrenic disorders. Biol Psychiatry 1984, 19:703-719.

137. Lohr JB, Caligiuri MP: Abnormalities in motor physiology in bipolar disorder. J Neuropsychiatry Clin Neurosci 2006, 18:342-349.

138. Swiecicki L, Zatorski P, Bzinkowska D, Sienkiewicz-Jarosz H, Szyndler J, Scinska A: Gustatory and olfactory function in patients with unipolar and bipolar depression. Prog Neuropsychopharmacol Biol Psychiatry 2009, 33:827-834

139. Negash A, Kebede D, Alem A, Melaku Z, Deyessa N, Shibire T, Fekadu A, Fekadu D, Jacobsson L, Kullgren G: Neurological soft signs in bipolar I disorder patients. J Affect Disord 2004, 80:221-230.

140. Rosenthal MZ, Ahn R, Geiger PJ: Reactivity to sensations in borderline personality disorder: a preliminary study. J Pers Disord 2011, 25:715-721.

141. Brown S, Shankar R, Smith K: Borderline personality disorder and sensory processing impairment. Prog Neurol Psychiatry 2009, 13:10-16.

142. Pavony MT, Lenzenweger MF: Somatosensory processing and borderline personality disorder features: a signal detection analysis of proprioception and exteroceptive sensitivity. J Pers Disord 2013, 27:208-221.

143. Swirsky-Sacchetti T, Gorton G, Samuel S, Sobel R, Genetta-Wadley A, Burleigh B: Neuropsychological function in borderline personality disorder. J Clin Psychol 1993, 49:385-396.

144. De la Fuente JM, Bengoetxea E, Navarro F, Bobes J, Alarcón RD: Interconnection between biological abnormalities in borderline personality disorder: use of the Bayesian networks model. Psychiatry Res 2011, 186:315-319

145. De la Fuente JM, Bobes J, Vizuete C, Bascaran MT, Morlán I, Mendlewicz J: Neurologic soft signs in borderline personality disorder. J Clin Psychiatry 2006, 67:541-546.

146. Gardner DL, Lucas PB, Cowdry RW: Soft sign neurological abnormalities in borderline personality disorder and normal control subjects. J Nerv Ment Dis 1987, 175:177-180.

147. Brown C, Cromwell RL, Filion D, Dunn W, Tollefson N: Sensory processing in schizophrenia: missing and avoiding information. Schizophr Res 2002, 55:187-195.

148. Cheng J, Han DY, Yao GZ, Wang Y, Wang YF: Balance function in schizophrenia patients. Chin Ment Health J 2012, 26:267-271.

149. Colbert EG, Koelgler RR, Markham CH: Vestibular dysfunction in childhood schizophrenia. AMA Arch Gen Psychiatry 1959, 1:600-617.

150. Emmerich DS, Levine FM: Differences in auditory sensitivity of chronic schizophrenic patients and normal controls determined by use of a forced-choice procedure. Dis Nerv Syst 1970, 31:552-557. 
151. Ghadirian AM, Butter HJ: Sensory perception and motoric reactivity in schizophrenic patients. J Clin Psychol 1978, 34:629-633.

152. Kent JS, Hong SL, Bolbecker AR, Klaunig MJ, Forsyth JK, O'Donnell BF, Hetrick WP: Motor deficits in schizophrenia quantified by nonlinear analysis of postural sway. PLoS One 2012, 7:e41808.

153. Kiss I, Fábián A, Benedek G, Kéri S: When doors of perception open: visual contrast sensitivity in never-medicated, first-episode schizophrenia. J Abnorm Psychol 2010, 119:586-593.

154. Levine FM, Whitney N: Absolute auditory threshold and threshold of unpleasantness of chronic schizophrenic patients and normal controls. J Abnorm Psychol 1970, 75:74-77.

155. Myers S, Caldwell D, Purcell G: Vestibular dysfunction in schizophrenia. Biol Psychiatry 1973, 7:255-261.

156. Ramage EM, Weintraub DM, Allen DN, Snyder JS: Evidence for stimulusgeneral impairments on auditory stream segregation tasks in schizophrenia. J Psychiatr Res 2012, 46:1540-1545.

157. Levy DL, Holzman PS, Proctor LR: Vestibular responses in schizophrenia. Arch Gen Psychiatry 1978, 35:972-981.

158. Günther W, Günther R, Eich FX, Eben E: Psychomotor disturbances in psychiatric patients as a possible basis for new attempts at differential diagnosis and therapy. II. Cross validation study on schizophrenic patients: persistence of a "psychotic motor syndrome" as possible evidence of an independent biological marker syndrome for schizophrenia. Eur Arch Psychiatry Neurol Sci 1986, 235:301-308.

159. Midorikawa A, Hashimoto $R$, Noguchi H, Saitoh O, Kunugi H, Nakamura K: Impairment of motor dexterity in schizophrenia assessed by a novel finger movement test. Psychiatry Res 2008, 159:281-289.

160. Sullivan EV, Shear PK, Zipursky RB, Sagar HJ, Pfefferbaum A: A deficit profile of executive, memory, and motor functions in schizophrenia. Biol Psychiatry 1994, 36:641-653

161. Tabarés-Seisdedos R, Salazar-Fraile J, Selva-Vera G, Balanzá-Martínez V, Ballester-Sánchez F, Cózar-Santiago R, Leal-Cercós C, Gómez-Beneyto M: Abnormal motor asymmetry only during bimanual movements in schizophrenic patients compared with healthy subjects. Schizophr Res 2003, 61:245-253.

162. Martin P, Tewesmeier M, Albers M, Schmid GB, Scharfetter $C$ : Towards an understanding of sensory soft signs in schizophrenia. Psychopathology 1995, 28:281-284

163. Compton MT, Bollini AM, McKenzie Mack L, Kryda AD, Rutland J, Weiss PS, Bercu Z, Esterberg ML, Walker EF: Neurological soft signs and minor physical anomalies in patients with schizophrenia and related disorders, their first-degree biological relatives, and non-psychiatric controls. Schizophr Res 2007, 94:64-73.

164. Mechri A, Bourdel MC, Slama H, Gourion D, Gaha L, Krebs MO: Neurological soft signs in patients with schizophrenia and their unaffected siblings: frequency and correlates in two ethnic and socioeconomic distinct populations. Eur Arch Psychiatry Clin Neurosci 2009, 259:218-226.

165. Chen YLR, Chen YHE, Mak FL: Soft neurological signs in schizophrenic patients and their nonpsychotic siblings. J Nerv Ment Dis 2000, 188:84-89.

166. Yazici AH, Demir B, Yazici KM, Göğüş A: Neurological soft signs in schizophrenic patients and their nonpsychotic siblings. Schizophr Res 2002, 58:241-246.

167. Aksoy-Poyraz C, Poyraz BÇ, Turan Ş, Arıkan MK: Minor physical anomalies and neurological soft signs in patients with schizophrenia and their siblings. Psychiatry Res 2011, 190:85-90.

168. Aydemir C, Goka E, Kisa C, Kurt A, Yuksel FV: Dyskinesia and soft neurological signs in schizophrenia: a comparative study. Int J Psychiatry Clin Pract 2005, 9:238-243.

169. Chan RCK, Chen EYH: Neurological abnormalities in Chinese schizophrenic patients. Behav Neurol 2007, 18:171-181

170. Flyckt L, Sydow O, Bjerkenstedt L, Edman G, Rydin E, Wiesel FA: Neurological signs and psychomotor performance in patients with schizophrenia, their relatives and healthy controls. Psychiatry Res 1999, 86:113-129.

171. Ismail B, Cantor-Graae E, McNeil TF: Neurological abnormalities in schizophrenic patients and their siblings. Am J Psychiatry 1998, 155:84-89.

172. Jaafari N, Baup N, Bourdel MC, Olié JP, Rotge JY, Wassouf I, Sharov I, Millet B, Krebs MO: Neurological soft signs in OCD patients with early age at onset, versus patients with schizophrenia and healthy subjects. J Neuropsychiatry Clin Neurosci 2011, 23:409-416.
173. Le Seac'h A, Picard H, Gorsane MA, Vidal PP, Amado I, Krebs MO: A step toward an objective quantification of subtle neurological signs in schizophrenia. Psychiatry Res 2012, 198:230-234.

174. Mohr F, Hubmann W, Cohen R, Bender W, Haslacher C, Hönicke S, Schlenker R, Wahlheim C, Werther P: Neurological soft signs in schizophrenia: assessment and correlates. Eur Arch Psychiatry Clin Neurosci 1996, 246:240-248.

175. Sevincok L, Akoglu A, Topaloglu B, Aslantas H: Neurological soft signs in schizophrenic patients with obsessive-compulsive disorder. Psychiatry Clin Neurosci 2004, 58:274-279.

176. Shibre T, Kebede D, Alem A, Kebreab S, Melaku Z, Deyassa N, Negash A Fekadu A, Fekadu D, Medhin G, Negeri C, Jacobsson L, Kullgren G: Neurological soft signs (NSS) in 200 treatment-naïve cases with schizophrenia: a community-based study in a rural setting. Nord J Psychiatry 2002, 56:425-431.

177. Venkatasubramanian G, Latha V, Gangadhar BN, Janakiramaiah N, Subbakrishna DK, Jayakumar PN, Keshavan MS: Neurological soft signs in never-treated schizophrenia. Acta Psychiatr Scand 2003, 108:144-146.

178. Walker E, Green M: Soft signs of neurological dysfunction in schizophrenia: an investigation of lateral performance. Biol Psychiatry 1982, 17:381-386.

179. Nucifora D, Calandra C: Soft neurological signs and apraxias in mood disorders and in schizophrenia. Minerva Psichiatr 1999, 40:147-158.

180. Bloch MH, Sukhodolsky DG, Dombrowski PA, Panza KE, Craiglow BG, Landeros-Weisenberger A, Leckman JF, Peterson BS, Schultz RT: Poor fine-motor and visuospatial skills predict persistence of pediatric-onset obsessive-compulsive disorder into adulthood. J Child Psychol Psychiatry 2011, 52:974-983.

181. Dar R, Kahn DT, Carmeli R: The relationship between sensory processing, childhood rituals and obsessive-compulsive symptoms. J Behav Ther Exp Psychiatry 2012, 43:679-684

182. Rieke EF, Anderson D: Adolescent/adult sensory profile and obsessivecompulsive disorder. Am J Occup Ther 2009, 63:138-145.

183. Segalàs C, Labad J, Alonso P, Real E, Subirà M, Bueno B, Jiménez-Murcia $S$, Menchón JM: Olfactory identification and discrimination in obsessivecompulsive disorder. Depress Anxiety 2011, 28:932-940

184. Peng ZW, Xu T, Miao GD, He QH, Zhao Q, Dazzan P, Chan RCK. Neurological soft signs in obsessive-compulsive disorder: the effect of co-morbid psychosis and evidence for familiality. Prog Neuropsychopharmacol Biol Psychiatry 2012, 39:200-205.

185. Bolton D, Gibb W, Lees A, Raven P, Gray JA, Chen E, Shafran R: Neurological soft signs in obsessive compulsive disorder: standardised assessment and comparison with schizophrenia. Behav Neurol 1998, 11:197-204.

186. Mataix-Cols D, Alonso P, Hernández R, Deckersbach T, Savage CR, Menchón $\mathrm{JM}$, Vallejo J: Relation of neurological soft signs to nonverbal memory performance in obsessive-compulsive disorder. J Clin Exp Neuropsycho 2003, 25:842-851.

187. Hollander E, Schiffman E, Cohen B, Rivera-Stein MA, Rosen W, Gorman JM, Fyer AJ, Papp L, Liebowitz MR: Signs of central nervous system dysfunction in obsessive-compulsive disorder. Arch Gen Psychiatry 1990, 47:27-32.

188. Karadag F, Tumkaya S, Kırtaş D, Efe M, Alacam H, Oguzhanoglu NK: Neurological soft signs in obsessive compulsive disorder with good and poor insight. Prog Neuropsychopharmacol Biol Psychiatry 2011, 35:1074-1079.

189. Gallacher J, Ilubaera V, Ben-Shlomo Y, Bayer A, Fish M, Babisch W, Elwood P: Auditory threshold, phonologic demand, and incident dementia. Neurology 2012, 79:1583-1590.

190. Kato-Narita EM, Nitrini R, Radanovic M: Assessment of balance in mild and moderate stages of Alzheimer's disease: implications on falls and functional capacity [in English and Portuguese]. Arq Neuropsiquiatr 2011, 69(2A):202-207.

191. Leandri M, Cammisuli S, Cammarata S, Baratto L, Campbell J, Simonini M, Tabaton M: Balance features in Alzheimer's disease and amnestic mild cognitive impairment. J Alzheimers Dis 2009, 16:113-120.

192. Pettersson AF, Engardt M, Wahlund LO: Activity level and balance in subjects with mild Alzheimer's disease. Dement Geriatr Cogn Disord 2002, $13: 213-216$.

193. Pettersson AF, Olsson E, Wahlund LO: Motor function in subjects with mild cognitive impairment and early Alzheimer's disease. Dement Geriatr Cogn Disord 2005, 19:299-304

194. Rolland Y, Abellan van Kan G, Nourhashemi F, Andrieu S, Cantet C, Guyonnet-Gillette S, Vellas B: An abnormal "one-leg balance" test predicts 
cognitive decline during Alzheimer's disease. J Alzheimers Dis 2009, 16:525-531.

195. Waite LM, Broe GA, Grayson DA, Creasey H: Motor function and disability in the dementias. Int J Geriatr Psychiatry 2000, 15:897-903.

196. Suttanon P, Hill KD, Said CM, LoGiudice D, Lautenschlager NT, Dodd KJ: Balance and mobility dysfunction and falls risk in older people with mild to moderate Alzheimer disease. Am J Phys Med Rehabil 2012, 91:12-23.

197. Kluger A, Gianutsos JG, Golomb J, Ferris SH, George AE, Franssen E, Reisberg B: Patterns of motor impairment in normal aging, mild cognitive decline, and early Alzheimer's disease. J Gerontol B Psychol Sci Soc Sci 1997, 52B:P28-P39.

198. Kluger A, Gianutsos JG, Golomb J, Ferris SH, Reisberg B: Motor/ psychomotor dysfunction in normal aging, mild cognitive decline, and early Alzheimer's disease: diagnostic and differential diagnostic features. Int Psychogeriatr 1997, 9(Suppl 1):307-321.

199. Oakley F, Duran L, Fisher A, Merritt B: Differences in activities of daily living motor skills of persons with and without Alzheimer's disease. Aust Occup Ther J 2003, 50:72-78.

200. Ott BR, Ellias SA, Lannon MC: Quantitative assessment of movement in Alzheimer's disease. J Geriatr Psychiatry Neurol 1995, 8:71-75.

201. Lam LCW, Lui WWC, Chu HFK: Association between soft neurological signs and clinical progression in Alzheimer's disease. Hong Kong J Psychiatry 2005, 15:43-49.

202. Seidl U, Thomann PA, Schröder J: Neurological soft signs in nursing home residents with Alzheimer's disease. J Alzheimers Dis 2009, 18:525-532.

203. Gagnon I, Forget R, Sullivan SJ, Friedman D: Motor performance following a mild traumatic brain injury in children: an exploratory study. Brain Inj 1998, 12:843-853.

204. Galvin J, Froude EH, Imms C: Sensory processing abilities of children who have sustained traumatic brain injuries. Am J Occup Ther 2009, 63:701-709.

205. Katz-Leurer M, Rotem H, Lewitus H, Keren O, Meyer S: Relationship between balance abilities and gait characteristics in children with post-traumatic brain injury. Brain Inj 2008, 22:153-159.

206. Kuhtz-Buschbeck JP, Hoppe B, Gölge M, Dreesmann M, Damm-Stünitz U, Ritz A: Sensorimotor recovery in children after traumatic brain injury: Analyses of gait, gross motor, and fine motor skills. Dev Med Child Neurol 2003, 45:821-828.

207. Cole KJ: Grasp force control in older adults. J Mot Behav 1991, 23:251-258.

208. Desrosiers J, Hébert R, Bravo G, Dutil E: Hand sensibility of healthy older people. J Am Geriatr Soc 1996, 44:974-978.

209. Fukunaga A, Uematsu H, Sugimoto K: Influences of aging on taste perception and oral somatic sensation. J Gerontol A Biol Sci Med Sci 2005 60A:109-113.

210. Li SC, Huxhold O, Schmiedek F: Aging and attenuated processing robustness: evidence from cognitive and sensorimotor functioning. Gerontology 2004, 50:28-34

211. Petrosino L, Fucci D: Temporal resolution of the aging tactile sensory system. Percept Mot Skills 1989, 68:288-290.

212. Pohl PS, Dunn W, Brown C: The role of sensory processing in the everyday lives of older adults. OTJR (Thorofare N J) 2003, 23:99-106.

213. Ranganathan VK, Siemionow V, Sahgal V, Yue GH: Effects of aging on hand function. J Am Geriatr Soc 2001, 49:1478-1484.

214. Schumm LP, McClintock M, Williams S, Leitsch S, Lundstrom J, Hummel T, Lindau ST: Assessment of sensory function in the National Social Life, Health, and Aging Project. J Gerontol B Psychol Sci Soc Sci 2009, 64B(Suppl 1):i76-i85

215. Shimokata $H$, Kuzuya F: Two-point discrimination test of the skin as an index of sensory aging. Gerontology 1995, 41:267-272.

216. Stevens JC: Aging and spatial acuity of touch. J Gerontol 1992, 47:P35-P40.

217. Stevens JC, Cruz LA: Spatial acuity of touch: ubiquitous decline with aging revealed by repeated threshold testing. Somatosens Mot Res 1996, 13:1-10.

218. Zhang Z, Francisco EM, Holden JK, Dennis RG, Tommerdahl M Somatosensory information processing in the aging population. Front Aging Neurosci 2011, 3:18.

219. Elsner RJF: Odor threshold, recognition, discrimination and identification in centenarians. Arch Gerontol Geriatr 2001, 33:81-94.

220. Bartoshuk LM, Rifkin B, Marks LE, Bars P: Taste and aging. J Gerontol 1986, 41:51-57.

221. Ashendorf L, Vanderslice-Barr JL, McCaffrey RJ: Motor tests and cognition in healthy older adults. App/ Neuropsychol 2009, 16:171-176.
222. Bennett SJ, Elliott D, Rodacki A: Movement strategies in vertical aiming of older adults. Exp Brain Res 2012, 216:445-455.

223. Kauranen $\mathrm{K}$, Vanharanta $\mathrm{H}$ : Influences of aging, gender, and handedness on motor performance of upper and lower extremities. Percept Mot Skills 1996, 82:515-525.

224. Smith CD, Umberger GH, Manning EL, Slevin JT, Wekstein DR, Schmitt FA, Markesbery WR, Zhang Z, Gerhardt GA, Kryscio RJ, Gash DM: Critical decline in fine motor hand movements in human aging. Neurology 1999, 53:1458-1461.

225. Vernazza-Martin S, Tricon V, Martin N, Mesure S, Azulay JP, Le Pellec-Muller A: Effect of aging on the coordination between equilibrium and movement: What changes? Exp Brain Res 2008, 187:255-265.

226. Kleinman M: The Effects of Aging on Motor Performance (ERIC ED230488). Washington, DC: ERIC Clearinghouse; 1982. Available at http://eric.ed.gov/? id=ED230488

227. Santos S, Gehring PR, Bertolassi MA, De Souza Nunes ME, Basso L, Meira CM $\mathrm{Jr}$ : Motor performance and aging: Is there any difference between 60 and 86 years old? J Sport Exerc Psychol 2007, 29(Suppl):S43

228. Chan RCK, Xu T, Li HJ, Zhao Q, Liu HH, Wang Y, Yan C, Cao XY, Wang YN, Shi YF, Dazzan P: Neurological abnormalities and neurocognitive functions in healthy elder people: a structural equation modeling analysis. Behav Brain Funct 2011, 7:32.

229. Rogers SJ: What are infant siblings teaching us about autism in infancy? Autism Res 2009, 2:125-137.

230. Hempel MS: Neurological development during toddling age in normal children and children at risk of developmental disorders. Early Hum Dev 1993, 34:47-57.

231. Bhat AN, Galloway JC, Landa RJ: Relation between early motor delay and later communication delay in infants at risk for autism. Infant Behav Dev 2012, 35:838-846.

232. Bryson SE, Zwaigenbaum L, Brian J, Roberts W, Szatmari P, Rombough V, McDermott C: A prospective case series of high-risk infants who developed autism. J Autism Dev Disord 2007, 37:12-24.

233. Mulligan S, White BP: Sensory and motor behaviors of infant siblings of children with and without autism. Am J Occup Ther 2012, 66:556-566.

234. Landa RJ, Gross AL, Stuart EA, Bauman M: Latent class analysis of early developmental trajectory in baby siblings of children with autism. J Child Psychol Psychiatry 2012, 53:986-996.

235. Landa R, Garrett-Mayer E: Development in infants with autism spectrum disorders: a prospective study. J Child Psychol Psychiatry 2006, 47:629-638.

236. Landa RJ, Gross AL, Stuart EA, Faherty A: Developmental trajectories in children with and without autism spectrum disorders: the first 3 years. Child Dev 2013, 84:429-442

237. Kroes M, Kessels AGH, Kalff AC, Feron FJM, Vissers YL, Jolles J, Vles JSH: Quality of movement as predictor of ADHD: results from a prospective population study in 5- and 6-year-old children. Dev Med Child Neurol 2002, 44:753-760.

238. Viholainen $H$, Ahonen $T$, Lyytinen $P$, Cantell M, Tolvanen A, Lyytinen H: Early motor development and later language and reading skills in children at risk of familial dyslexia. Dev Med Child Neurol 2006, 48:367-373.

239. Viholainen $H$, Ahonen $T$, Cantell $M$, Lyytinen $P$, Lyytinen $H$ : Development of early motor skills and language in children at risk for familial dyslexia. Dev Medicine Child Neurol 2002, 44:761-769.

240. Cannon M, Jones P, Huttunen MO, Tanskanen A, Murray RM: Motor coordination deficits as predictors of schizophrenia among Finnish school children. Hum Psychopharmacol 1999, 14:491-497.

241. Murray GK, Jones PB, Moilanen K, Veijola J, Miettunen J, Cannon TD, Isohanni M: Infant motor development and adult cognitive functions in schizophrenia. Schizophr Res 2006, 81:65-74

242. Schiffman J, Sorensen HJ, Maeda J, Mortensen EL, Victoroff J, Hayashi K, Michelsen NM, Ekstrom M, Mednick S: Childhood motor coordination and adult schizophrenia spectrum disorders. Am J Psychiatry 2009, 166:1041-1047.

243. Walker $E$, Lewine RJ: Prediction of adult-onset schizophrenia from childhood home movies of the patients. Am J Psychiatry 1990, 147:1052-1056.

244. Rosso IM, Bearden CE, Hollister JM, Gasperoni TL, Sanchez LE, Hadley T, Cannon TD: Childhood neuromotor dysfunction in schizophrenia patients and their unaffected siblings: a prospective cohort study. Schizophr Bull 2000, 26:367-378.

245. Watkins JM, Asarnow RF, Tanguay PE: Symptom development in childhood onset schizophrenia. J Child Psychol Psychiatry 1988, 29:865-878. 
246. Clarke MC, Tanskanen A, Huttunen M, Leon DA, Murray RM, Jones PB, Cannon M: Increased risk of schizophrenia from additive interaction between infant motor developmental delay and obstetric complications: evidence from a population-based longitudinal study. Am J Psychiatry 2011, 168:1295-1302.

247. Fish B, Dixon WJ: Vestibular hyporeactivity in infants at risk for schizophrenia: association with critical developmental disorders. Arch Gen Psychiatry 1978, 35:963-971.

248. Walker E, Lewis N, Loewy R, Palyo S: Motor dysfunction and risk for schizophrenia. Dev Psychopathol 1999, 11:509-523.

249. Gschwandtner U, Pflüger M, Aston J, Borgwardt S, Drewe M, Stieglitz RD, Riecher-Rössler A: Fine motor function and neuropsychological deficits in individuals at risk for schizophrenia. Eur Arch Psychiatry Clin Neurosci 2006, 256:201-206.

250. Koning JP, Tenback DE, Kahn RS, Vollema MG, Cahn W, van Harten PN: Movement disorders are associated with schizotypy in unaffected siblings of patients with non-affective psychosis. Psychol Med 2011, 41:2141-2147.

251. Mittal VA, Dhruv S, Tessner KD, Walder DJ, Walker EF: The relations among putative biorisk markers in schizotypal adolescents: minor physical anomalies, movement abnormalities, and salivary cortisol. Biol Psychiatry 2007, 61:1179-1186

252. Mittal VA, Neumann C, Saczawa M, Walker EF: Longitudinal progression of movement abnormalities in relation to psychotic symptoms in adolescents at high risk of schizophrenia. Arch Gen Psychiatry 2008, 65:165-171.

253. Neumann CS, Walker EF: Neuromotor functioning in adolescents with schizotypal personality disorder: associations with symptoms and neurocognition. Schizophr Bull 2003, 29:285-298.

254. Blanchard MM, Jacobson S, Clarke MC, Connor D, Kelleher I, Garavan H, Harley M, Cannon M: Language, motor and speed of processing deficits in adolescents with subclinical psychotic symptoms. Schizophr Res 2010, 123:71-76.

255. Chan RCK, Wang Y, Zhao Q, Yan C, Xu T, Gong Q, Manschreck TC: Neurological soft signs in individuals with schizotypal personality features. Aust N Z J Psychiatry 2010, 44:800-804.

256. Chang BP, Lenzenweger MF: Somatosensory processing in the biological relatives of schizophrenia patients: a signal detection analysis of twopoint discrimination. J Abnorm Psychol 2001, 110:433-442.

257. Chang BP, Lenzenweger MF: Somatosensory processing and schizophrenia liability: proprioception, exteroceptive sensitivity, and graphesthesia performance in the biological relatives of schizophrenia patients. J Abnorm Psychol 2005, 114:85-95

258. Marcus J, Hans SL, Auerbach JG, Auerbach AG: Children at risk for schizophrenia: the Jerusalem Infant Development Study. II. Neurobehavioral deficits at school age. Arch Gen Psychiatry 1993, 50:797-809.

259. Rieder RO, Nichols PL: Offspring of schizophrenics. III. Hyperactivity and neurological soft signs. Arch Gen Psychiatry 1979, 36:665-674

260. Fish B: An approach to prevention in infants at risk for schizophrenia: developmental deviations from birth to 10 years. J Am Acad Child Psychiatry 1976, 15:62-82.

261. Fish B, Hagin R: Visual-motor disorders in infants at risk for schizophrenia Arch Gen Psychiatry 1973, 28:900-904.

262. Egan MF, Hyde TM, Bonomo JB, Mattay VS, Bigelow LB, Goldberg TE, Weinberger DR: Relative risk of neurological signs in siblings of patients with schizophrenia. Am J Psychiatry 2001, 158:1827-1834.

263. Mechri A, Gassab L, Slama H, Gaha L, Saoud M, Krebs MO: Neurological soft signs and schizotypal dimensions in unaffected siblings of patients with schizophrenia. Psychiatry Res 2010, 175:22-26.

264. Picchioni MM, Toulopoulou T, Landau S, Davies N, Ribchester T, Murray RM: Neurological abnormalities in schizophrenic twins. Biol Psychiatry 2006, 59:341-348.

265. Prasad KM, Sanders R, Sweeney J, Montrose D, Diwadkar V, Dworakowski D, Miewald J, Keshavan M: Neurological abnormalities among offspring of persons with schizophrenia: relation to premorbid psychopathology. Schizophr Res 2009, 108(1):163-169.

266. Harjan A: Children of parents with affective disorders: developmental and behavior disorders, somatic and psychiatric care. Eur J Psychiatry 1989, 3:219-234

267. Pine D, Shaffer D, Schonfeld IS: Persistent emotional disorder in children with neurological soft signs. J Am Acad Child Adolesc Psychiatry 1993, 32:1229-1236.
268. Shaffer D, Schonfeld I, O'Connor PA, Stokman C, Trautman P, Shafer S, Ng S: Neurological soft signs: their relationship to psychiatric disorder and intelligence in childhood and adolescence. Arch Gen Psychiatry 1985 42:342-351.

269. Turner SM, Beidel DC, Roberson-Nay R: Offspring of anxious parents: reactivity, habituation, and anxiety-proneness. Behav Res Ther 2005, 43:1263-1279.

270. Sigurdsson E, van Os J, Fombonne E: Are impaired childhood motor skills a risk factor for adolescent anxiety? Results from the 1958 U.K. birth cohort and the National Child Development Study. Am J Psychiatry 2002, 159:1044-1046.

271. Sigurdsson E, Fombonne E, Sayal K, Checkley S: Neurodevelopmental antecedents of early-onset bipolar affective disorder. Br J Psychiatry 1999, 174:121-127.

272. Grisham JR, Fullana MA, Mataix-Cols D, Moffitt TE, Caspi A, Poulton R: Risk factors prospectively associated with adult obsessive-compulsive symptom dimensions and obsessive-compulsive disorder. Psychol Med 2011, 41:2495-2506.

273. Inzitari M, Carlo A, Baldereschi M, Pracucci G, Maggi S, Gandolfo C, Bonaiuto S, Farchi G, Scafato E, Carbonin P, Inzitari D: ILSA Working Group: Risk and predictors of motor-performance decline in a normally functioning population-based sample of elderly subjects: the Italian Longitudinal Study on Aging. J Am Geriatr Soc 2006, 54:318-324.

274. Aggarwal NT, Wilson RS, Beck TL, Bienias JL, Bennett DA: Motor dysfunction in mild cognitive impairment and the risk of incident Alzheimer disease. Arch Neurol 2006, 63:1763-1769.

275. Scarmeas N, Albert M, Brandt J, Blacker D, Hadjigeorgiou G, Papadimitriou A, Dubois B, Sarazin M, Wegesin D, Marder K, Bell K, Honig L, Stern Y: Motor signs predict poor outcomes in Alzheimer disease. Neurology 2005, 64:1696-1703.

276. Mittal VA, Tessner KD, Trottman HD, Esterberg M, Dhrub SH, Simeonova DI, McMillan AL, Murphy E, Saczawa ME, Walker EF: Movement abnormalities and the progression of prodromal symptomatology in adolescents at risk for psychotic disorders. J Abnorm Psychol 2007, 116:260-267.

277. Kremen WS, Koenen KC, Afari N, Lyons MJ: Twin studies of posttraumatic stress disorder: differentiating vulnerability factors from sequelae. Neuropharmacology 2012, 62:647-653.

278. Kinnealey M, Fuiek M: The relationship between sensory defensiveness, anxiety, depression and perception of pain in adults. Occup Ther Int 1999, 6:195-206.

279. Liss M, Timmel L, Baxley K, Killingsworth P: Sensory processing sensitivity and its relation to parental bonding, anxiety, and depression. Pers Individ Dif 2005, 39:1429-1439.

280. Goldsmith HH, Van Hulle CA, Arneson CL, Schreiber JE, Gernsbacher MA: A population-based twin study of parentally reported tactile and auditory defensiveness in young children. J Abnorm Child Psychol 2006, 34:378-392.

281. Engel-Yeger B, Dunn W: The relationship between sensory processing difficulties and anxiety level of healthy adults. Br J Occup Ther 2011, 74:210-216.

282. Piek JP, Barrett NC, Smith LM, Rigoli D, Gasson N: Do motor skills in infancy and early childhood predict anxious and depressive symptomatology at school age? Hum Mov Sci 2010, 29:777-786.

283. Pearsall-Jones JG, Piek JP, Rigoli D, Martin NC, Levy F: Motor disorder and anxious and depressive symptomatology: a monozygotic co-twin control approach. Res Dev Disabil 2011, 32:1245-1252.

284. Bart O, Bar-Haim Y, Weizman E, Levin M, Sadeh A, Mintz M: Balance treatment ameliorates anxiety and increases self-esteem in children with comorbid anxiety and balance disorder. Res Dev Disabil 2009, 30:486-495.

285. Kogan E, Lidor R, Bart O, Bar-Haim Y, Mintz M: Comorbidity between balance and anxiety disorders: verification in a normal population. J Psychol 2008, 142:601-613.

286. Lane SJ, Reynolds S, Thacker L: Sensory over-responsivity and ADHD: differentiating using electrodermal responses, cortisol, and anxiety. Front Integr Neurosci 2010, 4:8.

287. Liss M, Mailloux J, Erchull MJ: The relationships between sensory processing sensitivity, alexithymia, autism, depression, and anxiety. Pers Individ Dif 2008, 45:255-259.

288. Piek JP, Bradbury GS, Elsley SC, Tate L: Motor coordination and socialemotional behaviour in preschool-aged children. Int J Disabil Dev Educ 2008, 55:143-151. 
289. Robertson $A E$, Simmons DR: The relationship between sensory sensitivity and autistic traits in the general population. J Autism Dev Disord 2013, 43:775-784

290. Neal JA, Edelmann RJ, Glachan M: Behavioural inhibition and symptoms of anxiety and depression: Is there a specific relationship with social phobia? Br J Clin Psychol 2002, 41:361-374.

291. Meyer B, Carver CS: Negative childhood accounts, sensitivity, and pessimism: a study of avoidant personality disorder features in college students. J Pers Disord 2000, 14:233-248.

292. Meyer B, Ajchenbrenner M, Bowles DP: Sensory sensitivity, attachment experiences, and rejection responses among adults with borderline and avoidant features. J Pers Disord 2005, 19:641-658.

293. Ben-Sasson A, Carter AS, Briggs-Gowan MJ: Sensory over-responsivity in elementary school: prevalence and social-emotional correlates. J Abnorm Child Psychol 2009, 37:705-716.

294. Gouze KR, Hopkins J, LeBailly SA, Lavigne JV: Re-examining the epidemiology of sensory regulation dysfunction and comorbid psychopathology. J Abnorm Child Psychol 2009, 37:1077-1087.

295. Stansfeld SA, Clark CR, Jenkins LM, Tarnopolsky A: Sensitivity to noise in a community sample: I. Measurement of psychiatric disorder and personality. Psychol Med 1985, 15:243-254.

296. Balaban CD: Neural substrates linking balance control and anxiety. Physiol Behav 2002, 77:469-475

297. Stam CJ, van Straaten ECW: The organization of physiological brain networks. Clin Neurophysiol 2012, 123:1067-1087.

298. Bullmore E, Sporns O: The economy of brain network organization. Nat Rev Neurosci 2012, 13:336-349.

299. van den Heuvel MP, Sporns O: Rich-club organization of the human connectome. J Neurosci 2011, 31:15775-15786.

300. Ahmadlou M, Rostami R, Sadeghi V: Which attention-deficit/hyperactivity disorder children will be improved through neurofeedback therapy? A graph theoretical approach to neocortex neuronal network of ADHD. Neurosci Lett 2012, 516:156-160.

301. Kitano H: Biological robustness. Nat Rev Genet 2004, 5:826-837.

302. Sporns O: Networks of the Brain. Cambridge, MA: MIT Press; 2011.

303. Achard S, Salvador R, Whitcher B, Suckling J, Bullmore E: A resilient, low-frequency, small-world human brain functional network with highly connected association cortical hubs. J Neurosci 2006, 26:63-72.

304. Bassett DS, Bullmore E: Small-world brain networks. Neuroscientist 2006, 12:512-523

305. Maffei A, Fontanini A: Network homeostasis: a matter of coordination. Curr Opin Neurobiol 2009, 19:168-173.

306. Binzegger T, Douglas RJ, Martin KA: Topology and dynamics of the canonical circuit of cat V1. Neural Netw 2009, 22:1071-1078.

307. Dosenbach NU, Fair DA, Cohen AL, Schlaggar BL, Petersen SE: A dualnetworks architecture of top-down control. Trends Cogn Sci 2008, 12:99-105.

308. Griffa A, Baumann PS, Thiran JP, Hagmann P: Structural connectomics in brain diseases. Neuroimage 2013, 80:515-526.

309. Liu Y, Liang M, Zhou Y, He Y, Hao Y, Song M, Yu C, Liu H, Liu Z, Jiang T: Disrupted small-world networks in schizophrenia. Brain 2008, 131:945-961.

310. Uhlhaas PJ, Singer W: The development of neural synchrony and largescale cortical networks during adolescence: relevance for the pathophysiology of schizophrenia and neurodevelopmental hypothesis. Schizophr Bull 2011, 37:514-523.

311. Rippon G, Brock J, Brown C, Boucher J: Disordered connectivity in the autistic brain: challenges for the 'new psychophysiology'. Int J Psychophysiol 2007, 63:164-172.

312. Pettersson-Yeo W, Allen P, Benetti S, McGuire P, Mechelli A: Dysconnectivity in schizophrenia: Where are we now? Neurosci Biobehav Rev 2011, 35:1110-1124

313. Boersma M, Kemner C, de Reus MA, Collin G, Snijders TM, Hofman D, Buitelaar JK, Stam CJ, van den Heuvel MP: Disrupted functional brain networks in autistic toddlers. Brain Connect 2013, 3:41-49.

314. Peters JM, Taquet M, Vega C, Jeste SS, Fernandez IS, Tan J, Nelson CA Nelson CA, Sahin M, Warfield SK: Brain functional networks in syndromic and non-syndromic autism: a graph theoretical study of EEG connectivity. BMC Med 2013, 11:54

315. Barttfeld P, Wicker B, Cukier S, Navarta S, Lew S, Sigman M: A big-world network in ASD: dynamical connectivity analysis reflects a deficit in long-range connections and an excess of short-range connections. Neuropsychologia 2011, 49:254-263.
316. Pollonini L, Patidar U, Situ N, Rezaie R, Papanicolaou AC, Zouridakis G: Functional connectivity networks in the autistic and healthy brain assessed using Granger causality. In Engineering in Medicine and Biology Society (EMBC), 2010 Annual International Conference of the IEEE. IEEE; 2010:1730-1733.

317. Wang L, Zhu C, He Y, Zang Y, Cao Q, Zhang H, Zhong Q, Wang Y: Altered small-world brain functional networks in children with attentiondeficit/hyperactivity disorder. Hum Brain Mapp 2009, 30:638-649.

318. Ahmadlou M, Adeli H, Adeli A: Graph theoretical analysis of organization of functional brain networks in ADHD. Clin EEG Neurosci 2012, 43:5-13.

319. Yu D: Additional brain functional network in adults with attentiondeficit/hyperactivity disorder: a phase synchrony analysis. PLOS One 2013, 8:e54516.

320. van den Heuvel MP, Mandl RC, Stam CJ, Kahn RS, Hulshoff Pol H: Aberrant frontal and temporal complex network structure in schizophrenia: a graph theoretical analysis. J Neurosci 2010, 30:15915-15926.

321. Wang Q, Su TP, Zhou Y, Chou KH, Chen IY, Jiang T, Lin CP: Anatomical insights into disrupted small-world networks in schizophrenia. Neuroimage 2012, 59:1085-1093.

322. Yu Q, Sui J, Rachakonda S, He H, Gruner W, Pearlson G, Kiehl KA, Calhoun VD: Altered topological properties of functional network connectivity in schizophrenia during resting state: a small-world brain network study. PLoS One 2011, 6:e25423.

323. Bassett DS, Bullmore E, Verchinski BA, Mattay VS, Weinberger DR, Meyer-Lindenberg A: Hierarchical organization of human cortical networks in health and schizophrenia. J Neurosci 2008, 28:9239-9248.

324. Zhang J, Wang J, Wu Q, Kuang W, Huang X, He Y, Gong Q: Disrupted brain connectivity networks in drug-naive, first-episode major depressive disorder. Biol Psychiatry 2011, 70:334-342.

325. Zhang T, Wang J, Yang Y, Wu Q, Li B, Chen L, Yue Q, Tang H, Yan C, Lui S, Huang $X$, Chan RC, Zang Y, He Y, Gong Q: Abnormal small-world architecture of top-down control networks in obsessive-compulsive disorder. J Psychiatry Neurosci 2011, 36:23-31.

326. Stam CJ, Jones BF, Nolte G, Breakspear M, Scheltens P: Small-world networks and functional connectivity in Alzheimer's disease. Cereb Cortex 2007, 17:92-99.

327. Supekar K, Menon V, Rubin D, Musen M, Greicius MD: Network analysis of intrinsic functional brain connectivity in Alzheimer's disease. PLoS Comput Biol 2008, 4:e1000100.

328. Stam CJ, de Haan W, Daffertshofer A, Jones BF, Manshanden I, van Cappellen van Walsum AM, Montez T, Verbunt JPA, de Munck JC, van Dijk BW, Berendse HW, Scheltens P: Graph theoretical analysis of magnetoencephalographic functional connectivity in Alzheimer's disease. Brain 2009, 132:213-224.

329. Sanz-Arigita EJ, Schoonheim MM, Damoiseaux JS, Rombouts SARB, Maris E, Barkhof F, Scheltens P, Stam CJ: Loss of 'small-world' networks in Alzheimer's disease: graph analysis of fMRI resting-state functional connectivity. PLoS One 2010, 5:e13788.

330. Pievani M, de Haan W, Wu T, Seeley WW, Frisoni GB: Functional network disruption in the degenerative dementias. Lancet Neurol 2011, 10:829-843.

331. Pandit AS, Expert $P$, Lambiotte $R$, Bonnelle $V$, Leech $R$, Turkheimer FE, Sharp DJ: Traumatic brain injury impairs small-world topology. Neurology 2013, 80:1826-1833.

332. Montembeault M, Joubert S, Doyon J, Carrier J, Gagnon JF, Monchi O, Lungu $\mathrm{O}$, Belleville S, Brambati SM: The impact of aging on gray matter structural covariance networks. Neuroimage 2012, 63:754-759.

333. Ferreira LK, Busatto GF: Resting-state functional connectivity in normal brain aging. Neurosci Biobehav Rev 2013, 37:384-400.

334. Yao Z, Zhang Y, Lin L, Zhou Y, Xu C, Jiang T: Alzheimer's Disease Neuroimaging Initiative: Abnormal cortical networks in mild cognitive impairment and Alzheimer's disease. PLoS Comput Biol 2010, 6:e1001006.

335. Belmonte MK, Gomot M, Baron-Cohen S: Visual attention in autism families: 'unaffected' sibs share atypical frontal activation. J Child Psychol Psychiatry 2010, 51:259-276.

336. Gogtay N, Vyas NS, Testa R, Wood SJ, Pantelis C: Age of onset of schizophrenia: perspectives from structural neuroimaging studies. Schizophr Bull 2011, 37:504-513.

337. Fornito A, Bullmore ET: Connectomic intermediate phenotypes for psychiatric disorders. Front Psychiatry 2012, 3:32.

338. Buldú JM, Bajo R, Maestú F, Castellanos N, Leyva I, Gil P, Sendiña-Nadal I, Almendral JA, Nevado A, del-Pozo F, Boccaletti S: Reorganization of functional networks in mild cognitive impairment. PLoS One 2011, 6:e19584. 
339. Pijnenburg YAL, van der Made $Y$, van Cappellen van Walsum $A M$, Knol DL, Scheltens P, Stam CJ: EEG synchronization likelihood in mild cognitive impairment and Alzheimer's disease during a working memory task. Clin Neurophysiol 2004, 115:1332-1339.

340. Wang J, Zuo X, Dai Z, Xia M, Zhao Z, Zhao X, Jia J, Han Y, He Y: Disrupted functional brain connectome in individuals at risk for Alzheimer's disease. Biol Psychiatry 2013, 73:472-481.

341. Nir T, Jahanshad N, Jack CR, Weiner MW, Toga AW, Thompson PM, the Alzheimer's Disease Neuroimaging Initiative (ADNI): Small world network measures predict white matter degeneration in patients with early-stage mild cognitive impairment. Proc IEEE Int Symp Biomed Imaging 2012, 2012:1405-1408.

342. Dazzan P, Soulsby B, Mechelli A, Wood SJ, Velakoulis D, Phillips LJ, Yung AR, Chitnis X, Lin A, Murray RM, McGorry PD, McGuire PK, Pantelis C: Volumetric abnormalities predating the onset of schizophrenia and affective psychoses: an MRI study in subjects at ultrahigh risk of psychosis. Schizophr Bull 2012, 38:1083-1091.

343. Chan RCK, Di X, McAlonan GM, Gong Q: Brain anatomical abnormalities in high-risk individuals, first-episode, and chronic schizophrenia: an activation likelihood estimation meta-analysis of illness progression. Schizophr Bull 2011, 37:177-188.

344. Lymer GKS, Job DE, William T, Moorhead J, McIntosh AM, Owens DGC, Johnstone EC, Lawrie SM: Brain-behaviour relationships in people at high genetic risk of schizophrenia. Neuroimage 2006, 33:275-285.

345. Shi F, Yap PT, Gao W, Lin W, Gilmore JH, Shen D: Altered structural connectivity in neonates at genetic risk for schizophrenia: a combined study using morphological and white matter networks. Neuroimage 2012, 62:1622-1633.

346. Jakab A, Emri M, Spisak T, Szeman-Nagy A, Beres M, Kis SA, Molnar P, Berenyi $E$ : Autistic traits in neurotypical adults: correlates of graph theoretical functional network topology and white matter anisotropy patterns. PLoS One 2013, 8:e60982.

347. Mulder MJ, van Belle J, van Engeland H, Durston S: Functional connectivity between cognitive control regions is sensitive to familial risk for ADHD. Hum Brain Mapp 2011, 32:1511-1518.

348. Dennis EL, Jahanshad N, Rudie JD, Brown JA, Johnson K, McMahon KL, de Zubicaray Gl, Montgomery G, Martin NG, Wright MJ, Bookheimer SY, Dapretto M, Toga AW, Thompson PM: Altered structural brain connectivity in healthy carriers of the autism risk gene, CNTNAP2. Brain Connect 2011, 1:447-459.

349. Dazzan P, Morgan KD, Chitnis X, Suckling J, Morgan C, Fearon P, McGuire PK, Jones PB, Leff J, Murray RM: The structural brain correlates of neurological soft signs in healthy individuals. Cereb Cortex 2006, 16:1225-1231.

350. Hirjak D, Wolf RC, Stieltjes B, Hauser T, Seidl U, Schröder J, Thomann PA: Cortical signature of neurological soft signs in recent onset schizophrenia. Brain Topogr 2013. doi:10.1007/s10548-013-0292-z.

351. Hirjak D, Wolf RC, Stieltjes B, Seidl U, Schröder J, Thomann PA: Neurological soft signs and subcortical brain morphology in recent onset schizophrenia. J Psychiatr Res 2012, 46:533-539.

352. Thomann PA, Roebel M, Dos Santos V, Bachmann S, Essig M, Schröder J: Cerebellar substructures and neurological soft signs in first-episode schizophrenia. Psychiatry Res 2009, 173:83-87.

353. Thomann PA, Wüstenberg T, Santos VD, Bachmann S, Essig M, Schröder J: Neurological soft signs and brain morphology in first-episode schizophrenia. Psychol Med 2009, 39:371-379.

354. Dazzan P, Morgan KD, Orr KG, Hutchinson G, Chitnis X, Suckling J, Fearon P, Salvo J, McGuire PK, Mallett RM, Jones PB, Leff J, Murray RM: The structural brain correlates of neurological soft signs in ÆESOP first-episode psychoses study. Brain 2004, 127:143-153.

355. Mouchet-Mages S, Rodrigo S, Cachia A, Mouaffak F, Olie JP, Meder JF, Oppenheim C, Krebs MO: Correlations of cerebello-thalamo-prefrontal structure and neurological soft signs in patients with first-episode psychosis. Acta Psychiatr Scand 2011, 123:451-458.

356. Bersani G, Quartini A, Paolemili M, Clemente R, lannitelli A, Di Biasi C, Gualdi $\mathrm{G}$ : Neurological soft signs and corpus callosum morphology in schizophrenia. Neurosci Lett 2011, 499:170-174.

357. Venkatasubramanian G, Jayakumar PN, Gangadhar BN, Keshavan MS: Neuroanatomical correlates of neurological soft signs in antipsychotic-naive schizophrenia. Psychiatry Res 2008, 164:215-222.
358. Bottmer C, Bachmann S, Pantel J, Essig M, Amann M, Schad LR, Magnotta V, Schröder J: Reduced cerebellar volume and neurological soft signs in first-episode schizophrenia. Psychiatry Res 2005, 140:239-250.

359. Kong L, Bachmann S, Thomann PA, Essig M, Schröder J: Neurological soft signs and gray matter changes: a longitudinal analysis in first-episode schizophrenia. Schizophr Res 2012, 134:27-32.

360. Janssen J, Diaz-Caneja A, Reig S, Bombín I, Mayoral M, Parellada M, Graell M, Moreno D, Zabala A, García Vázquez V, Desco M, Arango C: Brain morphology and neurological soft signs in adolescents with first-episode psychosis. Br J Psychiatry 2009, 195:227-233.

361. Heuser M, Thomann PA, Essig M, Bachmann S, Schröder J: Neurological signs and morphological cerebral changes in schizophrenia: an analysis of NSS subscales in patients with first episode psychosis. Psychiatry Res 2011, 192:69-76.

362. Reiersen AM, Constantino JN, Volk HE, Todd RD: Autistic traits in a population-based ADHD twin sample. J Child Psychol Psychiatry 2007, 48:464-472.

363. Prikryl R, Ceskova E, Kasparek T, Kucerova H: Neurological soft signs and their relationship to 1-year outcome in first-episode schizophrenia. Eur Psychiatry 2007, 22:499-504.

364. Andreasen NC: Brave New Brain: Conquering Mental Illness in the Era of the Genome. New York: Oxford University Press; 2001.

365. Anderson J: Sensory intervention with the preterm infant in the neonatal intensive care unit. Am J Occup Ther 1986, 40:19-26.

366. Blackburn S: Environmental impact of the NICU on developmental outcomes. J Pediatr Nurs 1998, 13:279-289.

367. Mahoney MC, Cohen Ml: Effectiveness of developmental intervention in the neonatal intensive care unit: implications for neonatal physical therapy. Pediatr Phys Ther 2005, 17:194-208.

368. Vogel GW, Vogel F, McAbee RS, Thurmond AJ: Improvement of depression by REM sleep deprivation: new findings and a theory. Arch Gen Psychiatry 1980, 37:247-253.

369. Pfeiffer BA, Koenig K, Kinnealey M, Sheppard M, Henderson L: Effectiveness of sensory integration interventions in children with autism spectrum disorders: a pilot study. Am J Occup Ther 2011, 65:76-85.

370. Baranek GT: Efficacy of sensory and motor interventions for children with autism. J Autism Dev Disord 2002, 32:397-422.

doi:10.1186/1866-1955-5-26

Cite this article as: Levit-Binnun et al:: Sensory and motor secondary symptoms as indicators of brain vulnerability. Journal of Neurodevelopmental Disorders 2013 5:26.

\section{Submit your next manuscript to BioMed Central and take full advantage of:}

- Convenient online submission

- Thorough peer review

- No space constraints or color figure charges

- Immediate publication on acceptance

- Inclusion in PubMed, CAS, Scopus and Google Scholar

- Research which is freely available for redistribution 